\title{
Transition of care for adolescents from paediatric services to adult health services
}

DOI:

10.1002/14651858.CD009794.pub2

Document Version

Final published version

Link to publication record in Manchester Research Explorer

\section{Citation for published version (APA):}

Campbell, F., Biggs, K., Aldiss, S. K., O'Neill, P. M., Clowes, M., Mcdonagh, J., While, A., \& Gibson, F. (2016).

Transition of care for adolescents from paediatric services to adult health services. Cochrane Database of

Systematic Reviews, O(4), [CD009794]. https://doi.org/10.1002/14651858.CD009794.pub2

\section{Published in:}

Cochrane Database of Systematic Reviews

\section{Citing this paper}

Please note that where the full-text provided on Manchester Research Explorer is the Author Accepted Manuscript or Proof version this may differ from the final Published version. If citing, it is advised that you check and use the publisher's definitive version.

\section{General rights}

Copyright and moral rights for the publications made accessible in the Research Explorer are retained by the authors and/or other copyright owners and it is a condition of accessing publications that users recognise and abide by the legal requirements associated with these rights.

\section{Takedown policy}

If you believe that this document breaches copyright please refer to the University of Manchester's Takedown Procedures [http://man.ac.uk/04Y6Bo] or contact uml.scholarlycommunications@manchester.ac.uk providing relevant details, so we can investigate your claim.

\section{OPEN ACCESS}




\section{(E) Cochrane Library}

Cochrane Database of Systematic Reviews

\section{Transition of care for adolescents from paediatric services to adult health services (Review)}

Campbell F, Biggs K, Aldiss SK, O’Neill PM, Clowes M, McDonagh J, While A, Gibson F

Campbell F, Biggs K, Aldiss SK, O’Neill PM, Clowes M, McDonagh J, While A, Gibson F.

Transition of care for adolescents from paediatric services to adult health services.

Cochrane Database of Systematic Reviews 2016, Issue 4. Art. No.: CD009794.

DOI: 10.1002/14651858.CD009794.pub2.

www.cochranelibrary.com 
TABLE OF CONTENTS

HEADER . . . . . . . . . . . . . . . . . . . . . . . . . . . . . . . . . . . . . . . 1

ABSTRACT . . . . . . . . . . . . . . . . . . . . . . . . . . . . . . . . . . . . . . . . . . . . . . . . . .

PLAIN LANGUAGE SUMMARY . . . . . . . . . . . . . . . . . . . . . . . . . . . . . . . . . . . .

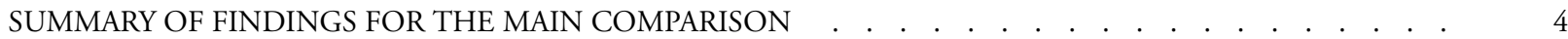

BACKGROUND . . . . . . . . . . . . . . . . . . . . . . . . . . . . . . . . . . . . . . . . . 6

OBJECTIVES . . . . . . . . . . . . . . . . . . . . . . . . . . . . . . . . . . . . . . . . . . . . . .

METHODS . . . . . . . . . . . . . . . . . . . . . . . . . . . . . . . .

Figure 1. . . . . . . . . . . . . . . . . . . . . . . . . . . . . . . . . . . . 10

RESULTS . . . . . . . . . . . . . . . . . . . . . . . . . . . . . . . . . . . . . . . 12

Figure 2. . . . . . . . . . . . . . . . . . . . . . . . . . . . . . . . . . . . . . 15

Figure 3. . . . . . . . . . . . . . . . . . . . . . . . . . . . . . . . . . . . . . 16

DISCUSSION . . . . . . . . . . . . . . . . . . . . . . . . . . . . . . . . . . . . . . . . . .

AUTHORS' CONCLUSIONS . . . . . . . . . . . . . . . . . . . . . . . . . . . . . . . . . . . . . .

ACKNOWLEDGEMENTS . . . . . . . . . . . . . . . . . . . . . . . . . . . . . . . . . . . . . . . 21

REFERENCES . . . . . . . . . . . . . . . . . . . . . . . . . . . . . . . . . . . . . . 21

CHARACTERISTICS OF STUDIES . . . . . . . . . . . . . . . . . . . . . . . . . . . . . . . . . 26

DATA AND ANALYSES . . . . . . . . . . . . . . . . . . . . . . . . . . . . . . . . . . . . . . . . . . . . . . . . . . .

Analysis 1.1. Comparison 1 Transtional care versus usual care, Outcome 1 PARS III. . . . . . . . . . . . . . . . . 38

Analysis 1.2. Comparison 1 Transtional care versus usual care, Outcome 2 Denyes Self-Care Practice Instrument (DSCPI 90()).

Analysis 1.3. Comparison 1 Transtional care versus usual care, Outcome 3 Community Life Skills Scale (CLSS). . . 39

Analysis 1.4. Comparison 1 Transtional care versus usual care, Outcome 4 Transition Readiness Assessment Questionnaire

(TRAQ).. . . . . . . . . . . . . . . . . . . . . . . . . . . . . . . . . . . . . . . . 40

Analysis 1.5. Comparison 1 Transtional care versus usual care, Outcome 5 TRAQ (self-management). . . . . . . . 40

Analysis 1.6. Comparison 1 Transtional care versus usual care, Outcome 6 TRAQ (Self-advocacy). . . . . . . . . . . 41

Analysis 1.7. Comparison 1 Transtional care versus usual care, Outcome 7 Health-related self-efficacy (PAM). . . . . 41

Analysis 1.8. Comparison 1 Transtional care versus usual care, Outcome 8 Patient initiated communications. $\quad . \quad$. $\quad 42$

Analysis 1.9. Comparison 1 Transtional care versus usual care, Outcome 9 MyHeart. . . . . . . . . . . . . . . . . 42

Analysis 1.10. Comparison 1 Transtional care versus usual care, Outcome 10 TRAQ (Self-advocacy). . . . . . . . . 43

Analysis 1.11. Comparison 1 Transtional care versus usual care, Outcome 11 Transfer from child to adolescent health services.

Analysis 1.12. Comparison 1 Transtional care versus usual care, Outcome 12 diabetes related hospitalizations in previous

12 months. . . . . . . . . . . . . . . . . . . . . . . . . . . . . . . . . . . . 44

APPENDICES . . . . . . . . . . . . . . . . . . . . . . . . . . . . . . . . . . . . . . 44

CONTRIBUTIONS OF AUTHORS . . . . . . . . . . . . . . . . . . . . . . . . . . . . . . . . . . . . . . . . . . .

DECLARATIONS OF INTEREST . . . . . . . . . . . . . . . . . . . . . . . . . . . . . . . . . . . . . 63

SOURCES OF SUPPORT . . . . . . . . . . . . . . . . . . . . . . . . . . . . . . . . . . . . . . . . . . . . . 64

DIFFERENCES BETWEEN PROTOCOL AND REVIEW . . . . . . . . . . . . . . . . . . . . . . . . . . . . 64

Transition of care for adolescents from paediatric services to adult health services (Review)

Copyright () 2016 The Cochrane Collaboration. Published by John Wiley \& Sons, Ltd. 


\title{
[Intervention Review]
}

\section{Transition of care for adolescents from paediatric services to adult health services}

\author{
Fiona Campbell ${ }^{1}$, Katie Biggs ${ }^{1}$, Susie K Aldiss ${ }^{2}$, Philip M O’Neill ${ }^{3}$, Mark Clowes ${ }^{1}$, Janet McDonagh ${ }^{4}$, Alison While ${ }^{5}$, Faith Gibson ${ }^{2}$ \\ ${ }^{1}$ School of Health and Related Research, University of Sheffield, Sheffield, UK. ${ }^{2}$ Department of Children's Nursing, London South \\ Bank University, London, UK. ${ }^{3}$ Sheffield Teaching Hospitals NHS Foundation Trust, Sheffield, UK. ${ }^{4}$ Centre for Musculoskeletal \\ Research, University of Manchester, Manchester, UK. ${ }^{5}$ Florence Nightingale School of Nursing and Midwifery, King's College London, \\ London, UK \\ Contact address: Fiona Campbell, School of Health and Related Research, University of Sheffield, Regent Street, Sheffield, S1 4DA, \\ UK. f.campbell@sheffield.ac.uk.
}

Editorial group: Cochrane Effective Practice and Organisation of Care Group.

Publication status and date: New, published in Issue 4, 2016.

Review content assessed as up-to-date: 19 June 2015.

Citation: Campbell F, Biggs K, Aldiss SK, O’Neill PM, Clowes M, McDonagh J, While A, Gibson F. Transition of care for adolescents from paediatric services to adult health services. Cochrane Database of Systematic Reviews 2016, Issue 4. Art. No.: CD009794. DOI: 10.1002/14651858.CD009794.pub2.

Copyright (C) 2016 The Cochrane Collaboration. Published by John Wiley \& Sons, Ltd.

\begin{abstract}
A B S T R A C T
Background

There is evidence that the process of transition from paediatric (child) to adult health services is often associated with deterioration in the health of adolescents with chronic conditions. Transitional care is the term used to describe services that seek to bridge this care gap. It has been defined as 'the purposeful, planned movement of adolescents and young adults with chronic physical and medical conditions from child-centred to adult-oriented health care systems'. In order to develop appropriate services for adolescents, evidence of what works and what factors act as barriers and facilitators of effective interventions is needed.
\end{abstract}

\section{Objectives}

To evaluate the effectiveness of interventions designed to improve the transition of care for adolescents from paediatric to adult health services.

\section{Search methods}

We searched The Cochrane Central Register of Controlled Trials 2015, Issue 1, (including the Cochrane Effective Practice and Organisation of Care Group Specialised Register), MEDLINE, EMBASE, PsycINFO, and Web of Knowledge to 19 June 2015. We also searched reference lists of included studies and relevant reviews, and contacted experts and study authors for additional studies.

\section{Selection criteria}

We considered randomised controlled trials (RCTs), controlled before- and after-studies (CBAs), and interrupted time-series studies (ITSs) that evaluated the effectiveness of any intervention (care model or clinical pathway), that aimed to improve the transition of care for adolescents from paediatric to adult health services. We considered adolescents with any chronic condition that required ongoing clinical care, who were leaving paediatric services and going on to receive services in adult healthcare units, and their families. Participating providers included all health professionals responsible for the care of young people.

Transition of care for adolescents from paediatric services to adult health services (Review)

Copyright $\odot 2016$ The Cochrane Collaboration. Published by John Wiley \& Sons, Ltd. 


\section{Data collection and analysis}

Two review authors independently extracted data from included papers, assessed the risk of bias of each study, and assessed the certainty of the evidence for the main comparisons using GRADE. Discrepancies were resolved by discussion. Authors were contacted for missing data. We reported the findings of the studies as pre- and post-intervention means and calculated the unadjusted absolute change from baseline with $95 \%$ confidence intervals (CI).

\section{Main results}

We included four RCTs ( $\mathrm{N}=238$ participants) that explored: a two-day workshop-based transition preparation training for adolescents with spina bifida; a nurse-led, one-on-one, teaching session with the additional support of a 'health passport' for adolescents with heart disease; a web- and SMS-based educational intervention for adolescents with a range of different conditions; and a structured comprehensive transition programme with a transition co-ordinator for adolescents with type 1 diabetes.

One study evaluating a one-on-one nurse-led intervention, and one evaluating a technology-based intervention suggested that these interventions may lead to slight improvements in transitional readiness and chronic disease self-management measured at six- to eightmonth follow-ups (low certainty evidence). Results with the TRAQ self-management tool were: MD 0.20 ; $95 \%$ CI -0.16 to 0.56 and MD 0.43; $95 \% \mathrm{CI} ;-0.09$ to 0.95 ; with the TRAQ self-advocacy tool: MD 0.37; $95 \% \mathrm{CI}-0.06$ to 0.80 ; and with the PAM tool were: MD 10; 95\% CI 2.96 to 17.04. In contrast, transition-preparation training delivered via a two-day workshop for patients with spina bifida may lead to little or no difference in measures of self-care practice and general health behaviours when measured using the DSCPI-90@.

Two studies evaluated the use of health services. One study evaluated a technology-based intervention and another a comprehensive transition programme; these interventions may lead to slightly more young people taking positive steps to initiate contact with health professionals themselves (Relative risk (RR): 4.87; 95\% CI 0.24 to 98.12 and RR 1.50; 95\% CI 0.32 to 6.94, respectively; low certainty evidence.

Young people's knowledge of their disease may slightly improve with a nurse-led, one-on-one intervention to prepare young people for transition to an adult congenital heart programme (MD 14; 95\% CI 2.67 to 25.33; one study; low certainty evidence).

Disease-specific outcome measures were reported in two studies, both of which led to little or no difference in outcomes (low certainty evidence). One study found little or no difference between intervention and control groups. A second study found that follow-up $\mathrm{HbA1c}$ in young people with type 1 diabetes mellitus increased by $1.2 \%$ for each percentage increase in baseline HbA1c, independent of treatment group $(1.2 \%$; $95 \%$ CI 0.4 to $1.9 ; \mathrm{P}=0.01)$.

Transition interventions may lead to little or no difference in well-being or quality of life as measured with the PARS III or PedsQ (two studies; low certainty evidence). Both the technology-based intervention and the two-day workshop for young people with spina bifida found little or no difference between intervention and control groups (MD 1.29; 95\% CI -4.49 to 7.07). One study did not report the data.

Four telephone support calls from a transition co-ordinator may lead to little or no difference in rates of transfer from paediatric to adult diabetes services (one study; low certainty evidence). At 12-month follow-up, there was little or no difference between groups of young people receiving usual care or a telephone support (RR $0.80 ; 95 \%$ CI 0.59 to 1.08 )). They may slightly reduce the risk of disease-related hospital admissions at 12-month follow-up (RR 0.29; 95\% CI 0.03 to 2.40).

\section{Authors' conclusions}

The available evidence (four small studies; $\mathrm{N}=238$ ), covers a limited range of interventions developed to facilitate transition in a limited number of clinical conditions, with only four to 12 months follow-up. These follow-up periods may not be long enough for any changes to become apparent as transition is a lengthy process. There was evidence of improvement in patients' knowledge of their condition in one study, and improvements in self-efficacy and confidence in another, but since few studies were eligible for this review, and the overall certainty of the body of this evidence is low, no firm conclusions can be drawn about the effectiveness of the evaluated interventions. Further research is very likely to have an important impact on our confidence in the intervention effect and likely could change our conclusions. There is considerable scope for the rigorous evaluation of other models of transitional care, reporting on clinical outcomes with longer term follow-up.

\section{PLAIN LANGUAGE SUMMARY}

Transition of care for adolescents from paediatric services to adult health services (Review) 
Interventions to improve the care of adolescents with long term health conditions as they transfer from child to adult health services.

\section{Background}

'Transition' describes the process of planning and moving from children's to adults' services. If this process is not well managed, adolescents with long-term health conditions sometimes fall into a gap in services, which can lead to deterioration in their health.

\section{Research question}

This review assessed the effectiveness of interventions to improve the transition of care for adolescents with chronic conditions and ongoing healthcare needs, as they transferred from child to adult health services.

\section{Study characteristics}

We searched the literature up to 19 June 2015 and found four studies ( $\mathrm{N}=238$ participants) for this review. The studies evaluated four different types of educational interventions, all targeting adolescents with different clinical conditions. All sought to improve knowledge and self-management skills of adolescents in preparation for transition to adult care.

\section{Key Results}

Three of the transitional-care programmes found that the intervention may slightly improve transitional readiness in young people, enabling them to better self-manage and adjust to using adult health services. One transitional-care programme that evaluated a twoday workshop for young people with spina bifida found little or no difference in measures of transitional readiness. Transitional-care programmes may slightly improve a young persons knowledge of their condition and their own appropriate use of health services. Transitional-care programmes led to little or no difference in health status, quality of life or well-being, or rates of transfer from child to adult health services.

\section{Certainty of the evidence}

While there is a wide range of transition programmes that are being developed in different countries, often within particular clinical specialties, this review only identified four small studies that provided low certainty evidence about educational interventions targeting participating adolescents, and no studies of interventions that targeted the organisation of care (for example, joint clinics or provision of a key worker). Other limitations with the evidence are the small number of adolescents recruited, the limited number of clinical conditions studied, the short follow up (12 months or less), and the fact that only two of the included studies reported on the primary outcome (that is, condition-specific clinical outcomes). Despite the challenges in designing studies that can test these types of interventions, such as evaluating a complex intervention, a stronger evidence base is needed to inform the development of these services. 
SUMMARY OF FINDINGS FOR THE MAIN COMPARISON [Explanation]

Interventions to improve transition of care

Patient or population: adolescents between 12 and 19 years with any chronic condition requiring ongoing clinical care, who are leaving or transitioning from paediatric to adult healthcare service

Settings: paediatric and adult healthcare services

Intervention: any transition of care or clinical pathway model designed to improve the transition of care

Comparison: usual care or other modified transitional-care model

\begin{tabular}{|c|c|c|c|}
\hline $\begin{array}{l}\text { Outcomes } \\
\text { (Tool used to measure) }\end{array}$ & $\begin{array}{l}\text { Mean difference }(95 \% \\
\mathrm{Cl})\end{array}$ & $\begin{array}{l}\text { No of Participants } \\
\text { (studies) }\end{array}$ & $\begin{array}{l}\text { Certainty of the evi- Comments } \\
\text { dence } \\
\text { (GRADE) }\end{array}$ \\
\hline
\end{tabular}

Transitional readiness, self-efficacy measures

\begin{tabular}{|c|c|c|c|c|}
\hline $\begin{array}{l}\text { Transitional readiness } \\
\text { (TRAQ) }\end{array}$ & $\begin{array}{l}\text { TRAQ: } \\
\text { 8-month follow-up } \\
\text { Mean difference (MD) } \\
0.20 ;(95 \% \mathrm{Cl}-0.16 \text { to } 0 . \\
56) \\
\text { TRAQ (self-manage- } \\
\text { ment) } \\
6 \text {-month follow-up } \\
\text { MD 0.43 ( } 95 \% \mathrm{Cl}-0.09 \\
\text { to 0.95) } \\
\text { TRAQ (self-advocacy) } \\
6 \text {-month follow-up } \\
\text { MD 0.37 ( } 95 \% \mathrm{Cl}-0.06 \\
\text { to 0.80) }\end{array}$ & $\begin{array}{l}155 \\
\text { ( } 2 \text { studies) }\end{array}$ & $\begin{array}{l}\oplus \oplus \bigcirc \bigcirc \\
\text { low }^{1}\end{array}$ & $\begin{array}{l}\text { Mackie } 2014 \text { did not } \\
\text { combine the results for } \\
\text { the two domains of the } \\
\text { TRAQ questionnaire }\end{array}$ \\
\hline $\begin{array}{l}\text { Patient Activation Mea- } \\
\text { sure (PAM) }\end{array}$ & $\begin{array}{l}\text { PAM: } \\
\text { MD at } 1 \text { to } 2 \text { months: } \\
10.00(95 \% \mathrm{Cl} 2.76 \text { to } \\
17.24) \\
M D \text { at } 2 \text { to } 8 \text { months: } \\
10.00(95 \% \mathrm{Cl} 2.96 \text { to } \\
17.04)\end{array}$ & $\begin{array}{l}75 \\
\text { (1 study) }\end{array}$ & $\begin{array}{l}\oplus \oplus \bigcirc \bigcirc \\
\text { low }^{2}\end{array}$ & \\
\hline $\begin{array}{l}\text { Community Life Skills } \\
\text { (CLSS) }\end{array}$ & $\begin{array}{l}\text { MD: } 0.77(95 \% \mathrm{Cl}-1.12 \\
\text { to } 2.66)\end{array}$ & $\begin{array}{l}65 \\
\text { (1 study }\end{array}$ & $\begin{array}{l}\oplus \oplus \bigcirc \bigcirc \\
\text { low }^{1}\end{array}$ & \\
\hline $\begin{array}{l}\text { Self-Care Practice } \\
\text { (Denyes Self-Care Prac- } \\
\text { tice Instrument (DSCPI) }\end{array}$ & $\begin{array}{l}\text { MD: }-3.70(95 \% \mathrm{Cl}-11 . \\
34 \text { to } 3.94)\end{array}$ & $\begin{array}{l}65 \\
\text { (1 study) }\end{array}$ & $\begin{array}{l}\oplus \oplus \bigcirc \bigcirc \\
\text { low }^{1}\end{array}$ & \\
\hline
\end{tabular}

Disease-specific outcomes

Transition of care for adolescents from paediatric services to adult health services (Review)

Copyright () 2016 The Cochrane Collaboration. Published by John Wiley \& Sons, Ltd. 


\begin{tabular}{|c|c|c|c|}
\hline $\begin{array}{l}\text { Disease specific status } \\
\text { (Activity index, clinical } \\
\text { inventory) }\end{array}$ & $\begin{array}{l}\text { Adolescents with } 101 \\
\text { chronic disease: } \\
\text { One study reported sim- } \\
\text { ilar values at } 8 \text {-month } \\
\text { follow-up (data not re- } \\
\text { ported) } \\
\text { HbA1c: } \\
\text { At 12-month follow- } \\
\text { up: } \\
\text { Median } 9.9 \text { (IQR } 7.6 \text { to } \\
\text { 10.6) }\end{array}$ & $\begin{array}{l}\oplus \oplus \bigcirc \bigcirc \\
\text { low }^{2}\end{array}$ & $\begin{array}{l}\text { Huang } 2014 \text { report } \\
\text { that no difference was } \\
\text { found in disease sta- } \\
\text { tus between groups at } \\
8 \text { months } \\
\text {. }\end{array}$ \\
\hline \multicolumn{4}{|l|}{ Well-being measures } \\
\hline $\begin{array}{l}\text { Well being/QOL (PARS } \\
\text { III, PedsQL) }\end{array}$ & $\begin{array}{l}\text { PARS: } \\
\text { MD } 1.29(95 \% \mathrm{Cl}-4.49 \text { (2 studies) } \\
\text { to } 7.07) \\
\text { PedsQL: } \\
\text { No outcome data re- } \\
\text { ported }\end{array}$ & $\begin{array}{l}\oplus \oplus \bigcirc \bigcirc \\
\text { low }^{2}\end{array}$ & \\
\hline \multicolumn{4}{|c|}{ Knowledge of disease and treatment } \\
\hline $\begin{array}{l}\text { Disease knowledge } \\
\text { (MyHeart) }\end{array}$ & $\begin{array}{ll}\text { MyHeart } & 50 \\
\text { MD at } 6 \text { months } 14.00 & \text { (1 study) } \\
(95 \% \mathrm{Cl} 2.67 \text { to } 25.33) & \end{array}$ & $\begin{array}{l}\oplus \oplus \bigcirc \bigcirc \\
\text { low }^{2}\end{array}$ & \\
\hline \multicolumn{4}{|l|}{ Use of health services } \\
\hline $\begin{array}{l}\text { Patient initiated health } \\
\text { care communication } \\
\text { (no tool) }\end{array}$ & $\begin{array}{l}\text { Relative risk (RR):4.87 } 101 \\
(95 \% \mathrm{Cl} 0.24 \text { to } 98.12) \text { (2 studies) } \\
\mathrm{RR}: 1.50(95 \% \mathrm{Cl} 0.32 \\
6.94)\end{array}$ & $\begin{array}{l}\oplus \oplus \bigcirc \bigcirc \\
\text { low }^{2}\end{array}$ & $\begin{array}{l}\text { data provided sepa- } \\
\text { rately for each study. }\end{array}$ \\
\hline $\begin{array}{l}\text { Transfer from paedi- } \\
\text { atric to adult services }\end{array}$ & $\begin{array}{l}\text { Transfer from paedi- } 26 \\
\text { atric to adult diabetes (1 study) } \\
\text { service: } \\
\text { Intervention: } 11 / 14 \\
(79 \%) \\
\text { Control: } 12 / 12(100 \%) \\
(P=0.2)\end{array}$ & $\begin{array}{l}\oplus \oplus \bigcirc \bigcirc \\
\text { low }^{2}\end{array}$ & $\begin{array}{l}\text { In adolescents with } \\
\text { T1DM }\end{array}$ \\
\hline $\begin{array}{l}\text { Healthcare resources } \\
\text { use }\end{array}$ & $\begin{array}{l}\text { Diabetes-related hospi- } 26 \\
\text { talisations in past } 12 \text { (1 study) } \\
\text { months } \\
\text { Intervention:1/14 }(7 . \\
1 \%) \\
\text { Control: } 3 / 12(25 \%)\end{array}$ & $\begin{array}{l}\oplus \oplus \bigcirc \bigcirc \\
\text { low }^{2}\end{array}$ & $\begin{array}{l}\text { In adolescents with } \\
\text { T1DM }\end{array}$ \\
\hline
\end{tabular}


GRADE Working Group grades of evidence

High quality: Further research is very unlikely to change our confidence in the estimate of effect.

Moderate quality: Further research is likely to have an important impact on our confidence in the estimate of effect and may change the estimate.

Low quality: Further research is very likely to have an important impact on our confidence in the estimate of effect and is likely to change the estimate.

Very low quality: We are very uncertain about the estimate.

${ }^{1}$ Evidence downgraded due to unclear risk of bias, inconsistency of findings and small studies

${ }^{2}$ Evidence downgraded due to limitations in study design and small studies

${ }^{3}$ Evidence downgraded due to small study and high risk of bias due to loss to follow-up

Cl: Confidence interval; RR: Risk ratio; MD: Mean difference

MyHeart: The MyHeart scale was developed for this study and consists of seven short questions. It is reported as a percentage correct score. It was developed for this study, was piloted to confirm face and content validity

PAM: Patient Activation Measures is a scale of 0 to 100, with 100 representing functioning as an independent adult with a chronic disease. A higher score indicates a more positive outcome.

PARS III: Personal Adjustment and Role Skills Scale is a tool that assesses subjective well-being. It contains 28 items.

PedsQL: Pedatric Quality of Life Scale is a generic assessment instrument that assesses patients' and parents' perceptions of health-related quality of life in patients with chronic health conditions.

TRAQ: Transition Readiness Assessment Questionnaire: TRAQ involves 33 questions assessing skills and actions from 2 domains: self-management and self-advocacy. A higher score indicates a more positive outcome.

T1DM: Type one diabetes mellitus

\section{B A C K G ROU N D}

The transition from adolescence to adulthood is a challenging time of physical, psychological, and social change. Young people with any form of disability, chronic disease, or significant mental health problems, face even greater challenges, since they also have to deal with important changes in the care they need and the way it is provided. The role of the young person and their parents or guardians alters as the adolescent wants, and is expected to, exercise greater independence in the management of their care.

Health services that fail to adequately meet the needs of young people and their families at this time of considerable change may result in a deterioration in health status that can have negative long-term consequences. Thus, the transfer of adolescents from paediatric (child) to adult services is a crucial time in the health of young people, who may potentially fall into a poorly managed 'care gap'. There is evidence that the process of transitioning from child to adult services is often associated with a deterioration in health of adolescents with chronic conditions (Busse 2007; Kipps 2002; Lotstein 2013; Moons 2009; Nakhla 2009; Reid 2004; Watson
2005; Yeung 2008). Many surveys of young people with various chronic conditions and their caregivers have reported the need for interventions to minimise the risks of deteriorating health status as children move to adult services (Lotstein 2005; Latzman 2011; Moons 2009; Shaw 2004;).

'Transitional care' is the term used to describe services that seek to bridge this 'care gap'. It has been defined as "the purposeful, planned movement of adolescents and young adults with chronic physical and medical conditions from child-centred to adult-oriented healthcare systems" (Blum 1993). Until recently, the literature on transition had a fairly limited focus on conditions such as diabetes and arthritis, but transition is now emerging as a priority across all long-term conditions. This shift is partly due to advances in health care, resulting in more young people with conditions, such as cystic fibrosis, now surviving into adulthood, but also to the growing realisation that services are failing to meet the needs of young people. Within the UK, it is argued that some of the issues around transition and the provision of developmentally appropriate care for young people, stem from lack of training for health 
professionals and the belief that adolescent health is not a distinct specialty, in contrast to many other European countries, Australia, New Zealand, Canada, and the USA (Gleeson 2012; McDonagh 2004; McDonagh 2006).

To prevent adolescents from becoming lost in the transfer between paediatric and adult health services is a major challenge for healthcare providers (Gleeson 2012; Viner 1999). These include, for example, maintaining open lines of communication between different service providers, professionals, young people themselves, and their families. Determining a young person's readiness to transfer to adult services, and tailoring services to the needs of adolescents rather than relying on physical age, may also present challenges. The diverse concerns of families and adolescents, whose abilities to take control are increasing, are complex; particularly for service providers within adult sectors where the majority of those receiving care are older people (for example, in the case of diabetes). The need to develop effective and efficient transitional care to prevent harmful deterioration in young peoples' health is supported by policy documents in the UK and the USA (AAP 2002; CPS 2006; CSCI 2007; DH 2004; DH 2006; DH 2010; DH 2013; RCN 2008; RCN Adolescent Health 2004; RCPCH 2003; RCPE 2008).

\section{Description of the condition}

The number of young people with chronic illnesses and disabilities entering adulthood, who may be in need of support services to achieve their physical, social, and psychological potential, is on the increase. This includes an increasing number of children with chronic diseases that require life-long management, who were not previously expected to reach adulthood (While 1996). For example, from 1982 to 2007, the proportion of individuals with cystic fibrosis achieving adulthood (older than 18 years of age) increased from $27 \%$ to $56 \%$ (Cystic Fibrosis Trust 2008). It is now estimated that a child born today with cystic fibrosis will survive into their fifties (Dodge 2007). Currently, almost $90 \%$ of children with congenital heart disease will survive into adulthood (Moons 2010). Furthermore, the prevalence of chronic illnesses such as asthma, diabetes (type 1 and 2), and obesity has increased. In the UK, one in seven young people (15\%) aged 11 to 15 report having been diagnosed with a long-term medical illness or disability, such as asthma, diabetes, epilepsy, cancer, or physical or mental impairment (Hagell 2015). This means that more children who need management of these conditions are moving from child to adult services.

Adolescence is also a time when adult behaviours become established and therefore, represents a window of opportunity to promote healthy behaviour and influence the public health burden of tomorrow's adults (DH 2006; Sawyer 2012). The integration of the core principles of adolescent medicine with self-management of chronic conditions, plus appropriate health service structures and professional training, are considered imperative for effective transitional care (Kennedy 2008). There is a risk that unless transitional care and adolescent health are well managed, this opportunity might be lost.

\section{Description of the intervention}

Transitional care differs from a single event, such as transfer. Preparation should start early in adolescence and extend beyond the day of discharge from paediatric services, until the young person feels well-established in adult services. This approach to care may comprise of different components and may be delivered over different time periods. The different components could include educational and training interventions, delivered to healthcare providers, the adolescents, their families, or a combination. It might include more structural changes, such as facilitating improved transfer of information, the development of adolescent clinics, or both. It could involve changes to professional roles, with the creation of professionals who work specifically with young people as they move from child to adult health services.

\section{How the intervention might work}

The literature describes a number of barriers to effective transitional care and suggest interventions that may mitigate them. Barriers include: abrupt or unplanned transfers to adult services, lack of confidence in adult services expressed by patients, their families, and paediatric care providers, structural problems that prevent reliable transfer of medical records (Gleeson 2012), lack of opportunities for young people to see clinicians independently of their parents (Suris 2009), inadequate communication between specialists, insufficient co-ordination of health services, lack of education and training of healthcare providers, insufficiently flexible services, failing to be responsive to, or aware of the needs of adolescents, insufficient co-ordination with adult services (Scal 2005), and failure to include adolescents in transition programs in ways that are meaningful to them (Kaufman 2006).

\section{Why it is important to do this review}

Young people with long-term healthcare needs are transferred from paediatric to adult services at a key time of change in their lives. Patterns of health behaviour are established during adolescence that remain into adult life (for example, smoking, dietary habits, levels of physical activity; Sawyer 2007; Sawyer 2012). For adolescents with existing long-term health needs, this period in their lives is often associated with a deterioration in their health status. As a result, improving the healthcare of young people has become a national priority in the UK (DH 1999; DH 2003; DH 2008; DH 2010; DH 2013). However, there is a lack of evidence to guide the development of transitional care (Crowley 2011; Kirk 2014; 
Lugasi 2011, Reid 2004; Watson 2011, While 2004). The Care Quality Commission review of services for young people moving from child to adult health services found that funding arrangements were fragmented (CQC 2014). A consequence of this was that some young people and their families were left without equipment, services, respite, or other requirements during transition. Professionals with no former knowledge of, or connection with the young person and their family sometimes conducted the healthcare assessments to determine how to allocate funds, resulting in delayed funding.

As well as an historical neglect of adolescent health care, transitional care is hampered by existing professional practices and boundaries, service configuration, and a poor understanding of appropriate models of transitional care (McDonagh 2006a; Viner 1999; While 2004). In a survey of paediatric diabetic services in the UK, it was found that $21 \%$ of services still organised the transfer of adolescents to adult care by letter only (Gosden 2010). In the USA, there has been only limited achievement of national health policy goals related to transition, despite consensus statements issued by the American Academy of Pediatrics, the American Academy of Family Physicians, the Americal College of Physicians, and other healthcare societies, stating the importance of supporting and facilitating the transition of adolescents with special healthcare needs into adulthood, and developing foundational guidance for healthcare processes to facilitate this (Snow 2009; US Department of Health and Human Services 2002). A national survey revealed that most paediatric practices neither initiate transition planning early in adolescence nor offer transitional support services. The survey authors noted that some of the factors leading to gaps in transitional support are due to limited staff training, lack of an identified staff person responsible for transition, financial barriers, and anxiety on the part of paediatricians, adolescents, and their parents about planning for their future health care (McManus 2008). The World Health Orgnaization (WHO) report Health for the world's adolescents: a second chance in the second decade reports that health services for adolescents in both high- and middle-low income countries are highly fragmented, poorly co-ordinated and uneven in quality (Dick 2015). Evidence suggests that adolescents experience many barriers to health care (WHO/UNAIDS (2015). This review addresses a critical aspect of adolescent health care, that of transition from child to adult services, and aims to identify the evidence to support the development of effective transitionalcare services

\section{O B JECT IVES}

To evaluate the effectiveness of interventions designed to improve the transition of care for adolescents from paediatric to adult health services.

\section{MET HODS}

\section{Criteria for considering studies for this review}

\section{Types of studies}

We considered randomised controlled trials (RCTs), controlled before- and after-studies (CBAs), and interrupted time-series studies (ITSs) evaluating the effectiveness of interventions that aimed to improve the transition of care for adolescents from paediatric to adult health services. We included CBAs only if they had at least two intervention and two control sites. We included ITSs if they had a clearly defined point in time when the intervention occurred and three data collection points before and after the intervention.

\section{Types of participants}

We included adolescents with conditions that required ongoing clinical care (for example, diabetes mellitus, cystic fibrosis, muscular dystrophy, congenital heart disease, cerebral palsy, autism, juvenile idiopathic arthritis, solid organ transplantation, and epilepsy), who would be leaving paediatric services and would require ongoing services in adult healthcare units, or had already transferred to adult services, and their families, parents, or guardians,

There was no restriction on the age of the participants to avoid excluding studies that may involve children younger than 12 years, as transition interventions may begin in advance of the actual transfer. Thus, we also considered transition interventions that had begun before children reached adolescence. However, for the purpose of this review, the term 'adolescence' refers to young people aged between 12 and 19 years.

Participating providers included all health professionals who may be responsible for the care of young people.

\section{Types of interventions}

We considered any care (or clinical pathway) model aimed at improving the transition of care for adolescents from paediatric to adult health services (for example, dedicated adolescent units, joint clinics, the use of specialised key workers). We included transitional-care models independent of the duration of the interventions or the time points of the intervention (some start at an early stage, when a child is 12 to 14 years old; other others may start when the child is 15 or 16 years old).

Comparator interventions included current practice, usual care, or a modified version of the intervention. We also considered trials that compared different transitional-care models. 


\section{Types of outcome measures}

\section{Primary outcomes}

Disease-specific patient outcomes or status, using validated measures, for example, glycated haemoglobin (HbA1c), lung function, disease-specific patient-reported outcomes (PROMs).

\section{Secondary outcomes}

- Transitional readiness

- Patient satisfaction

- Treatment adherence

- Health-related quality of life

- Disease-related knowledge

- Self-advocacy skills

- Improved documentation of transitional issues

- Unanticipated or adverse outcomes

- Healthcare resource use and cost data

\section{Search methods for identification of studies}

We searched electronic databases and reference lists of relevant papers to identify studies matching the inclusion criteria.

\section{Electronic searches}

Information Scientist, N. Roberts developed the search strategies in consultation with the review authors. We searched the Cochrane Database of Systematic Reviews and the Database of Abstracts of Reviews of Effects (DARE) from inception to June (week 2) 2015 for related systematic reviews, and the databases listed below for primary studies. The electronic databases were searched using the search strategies described in Appendix 1. We did not restrict the searches by language or publication status.

- Cochrane Central Register of Controlled Trials (CENTRAL; The Cochrane Library 2015, Issue1, which included the Cochrane Effective Practice and Organisation of Care (EPOC) Group Specialised Register)
- MEDLINE via Ovid (beginning 1946 to June 2015);

- EMBASE via Ovid (beginning 1974 to June 2015)

- CINAHL via EBSCO (beginning 1982 to June 2015)

- PsycINFO via Ovid (beginning 1967 to June 2015);

- HMIC (Health Management Information Consortium; beginning 1979 to June 2015);

- Web of Science (beginning 1945 to June 2015).

\section{Searching other resources}

We searched the reference lists of included studies and nine existing relevant reviews (Binks 2007; Bloom 2012; Crowley 2011; Doug 2011; Fegran 2014; Fleming 2002; Forbes 2002; Lugasi 2011; Paul 2014). We also performed a cited reference search for included studies. We contacted content experts to identify unpublished or ongoing work and searched websites of relevant professional bodies, including the Royal College of Nursing, American Academy of Pediatrics, and the Royal College of Paediatrics.

\section{Data collection and analysis}

\section{Selection of studies}

We downloaded all titles and abstracts identified by the electronic searches into the reference management database Reference Manager and removed duplicates (Reference Manager 2010). Four review authors (FC, SA, KB, PoN) independently screened the remaining citations. We excluded studies that did not meet the inclusion criteria, and retrieved the full text of citations that appeared relevant, or where relevance was unclear. The same four review authors independently assessed the eligibility of the retrieved papers. Disagreements were resolved by discussion among review authors. Each study excluded at the full-paper screening was described in the Characteristics of excluded studies table, along with the reason for exclusion. We used a PRISMA study flow chart to summarise the number of papers included and excluded at each stage (Moher 2009). See Figure 1 
Figure I. Study flow diagram.

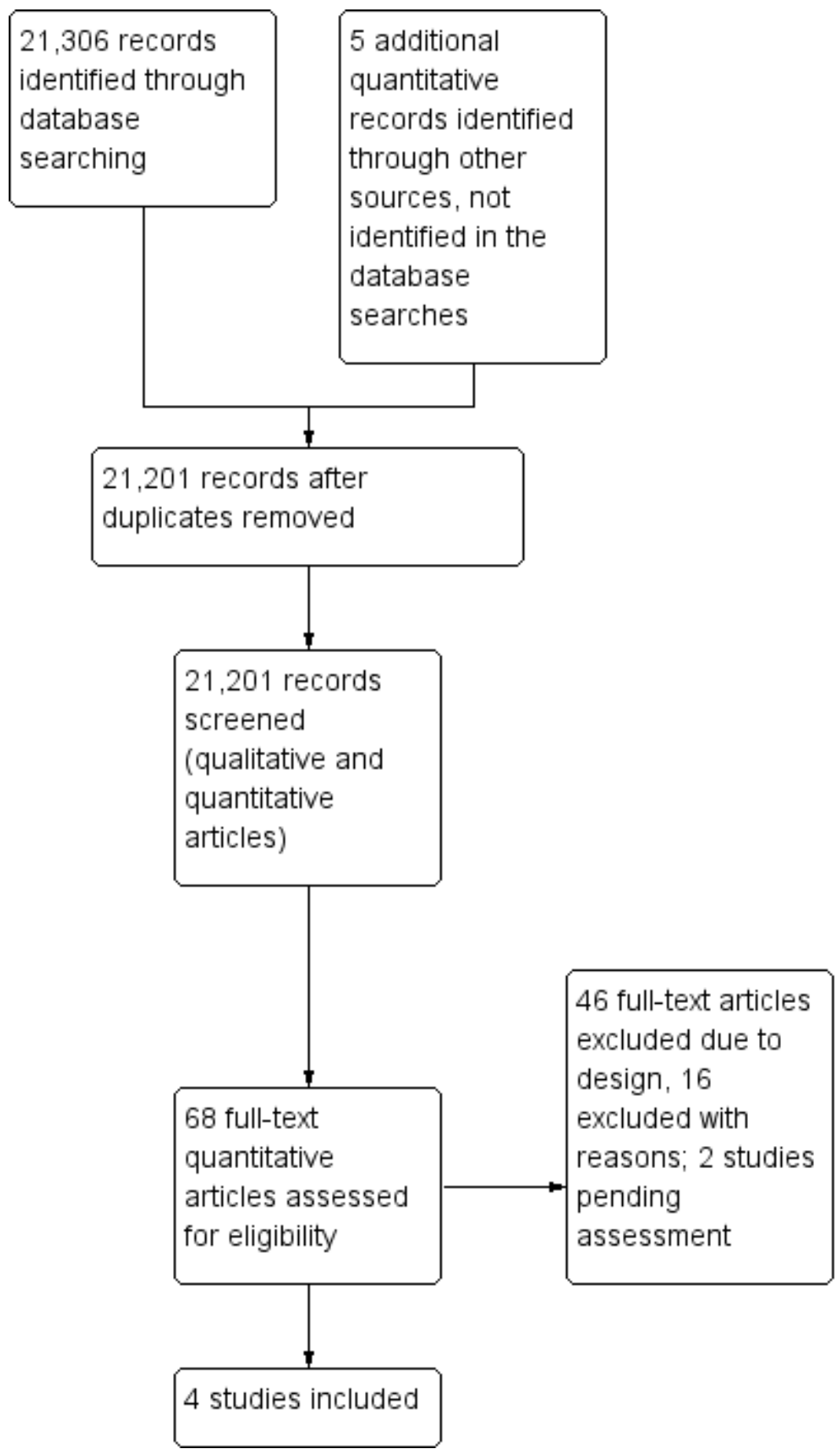




\section{Data extraction and management}

Three review authors (FC, SA, KB) independently extracted data onto a revised and piloted EPOC group data extraction form ( EPOC 2011). Differences in data extracted were explored and resolved by discussion among the reviewer authors. Data extracted from the included studies included: setting (country, location, provider, site of provision), methods (study design, methods of measuring outcomes, assessment of confounders), intervention (focus, funding, context, attributes, duration, service configuration), and outcomes (including harmful effects).

\section{Assessment of risk of bias in included studies}

The review authors independently evaluated the risk of bias using the Cochrane tool for assessing risk of bias on seven criteria; (i) adequate sequence generation; (ii) concealment of allocation; (iii) blinded or objective assessment of primary outcomes; (iv) adequately addressed incomplete outcome data; (v) free from selective reporting; (vi) free of other risk of bias, including generalisability of participants and length of follow-up; (vii) similar baseline characteristics (Higgins 2008). We categorised the risk of bias for these criteria as low, unclear, or high. We considered studies to be at an overall low risk of bias if all risk of bias criteria were judged as 'adequate' methodology. We judged the risk of bias to be high when there were one of the following; inadequate methods of randomisation and allocation concealment, a lack of blinding of the outcome assessment, the use of subjective patient-reported outcome measures, and the absence of similarity between groups at baseline.

We summarised the risk of bias of the included studies in the text and presented it in the 'Risk of bias' section within the Characteristics of included studies table.

\section{Measures of treatment effect}

We did not pool the data due to the heterogeneity of the interventions and the different methods of measuring and reporting the outcome variables. We reported the data in natural units, reporting pre-intervention and post-intervention means for both study and control groups, and we calculated the unadjusted absolute change from baseline with $95 \%$ confidence intervals (CI).

\section{Unit of analysis issues}

There were no unit of analysis issues; the one cluster-RCT included in the review accounted for clustering in their analysis (Mackie 2014).

\section{Dealing with missing data}

We contacted authors for full details of the research where we could only find the abstracts, or for missing data in published research.

\section{Assessment of heterogeneity}

The study populations and interventions in the four included studies differed; we describe these differences and did not test for statistical heterogeneity as we did not combine study data. If, in future updates, a sufficient number of studies are included, we will describe clinical and methodological diversity across the studies, and will undertake meta-analysis if there are sufficiently homogeneous studies in terms of participants, intervention, and outcomes to provide meaningful summaries. Where meta-analyses are possible, we will assess statistical heterogeneity using the $\mathrm{Chi}^{2}$ test and explore heterogeneity in sub-group analyses (Higgins 2003).

\section{Assessment of reporting biases}

We were unable to test for reporting biases using funnel plot asymmetry because of the small number of studies identified for inclusion ( $\mathrm{N}=4$; Egger 1997).

\section{Data synthesis}

We described the results of individual studies. We did not pool the data from the included studies due to the heterogeneity of interventions and populations. If a sufficient number of homogenous studies are found in future updates, we shall undertake data synthesis using meta-analyses, as per our protocol.

We assessed the certainty of the evidence for each important outcome using the Grading of Recommendations Assessment, Development and Evaluation (GRADE) approach (Guyatt 2008). We downgraded the certainty for: study limitations, inconsistency of results, imprecision, indirectness of evidence, and publication bias. and presented the main findings in a 'Summary of findings' table.

\section{Subgroup analysis and investigation of heterogeneity}

We did not perform a subgroup analysis, nor did we quantitatively assess heterogeneity.

\section{Sensitivity analysis}

We did not perform a sensitivity analysis. 


\section{RE S U L T S}

\section{Description of studies}

\section{Results of the search}

See study flow chart Figure 1. The electronic database searches and other sources yielded 21,201 citations after duplicates were removed. From our review of these abstracts, 68 studies appeared to meet the eligibility criteria and were retrieved for further assessment. We excluded 46 full-text articles that clearly did not meet the eligibility criteria and we excluded 16 with reasons. See Characteristics of excluded studies table.

Four studies, recruiting a total of 238 participants, met the inclusion criteria and were included in the review. All of the papers were published in English.

We contacted the authors of two potentially eligible studies identified through conference abstracts, to request data. These have not been incorporated into the review and are currently pending assessment (Puri 2009; Shipp 2011). See:Characteristics of studies awaiting classification table.

\section{Included studies}

\section{Study design}

Four randomised controlled studies met the inclusion criteria (Betz 2010; Huang 2014; Mackie 2014; Steinbeck 2014). One of these was a cluster-randomised design trial, which the authors reported taking into account in the analyses of the data (Mackie 2014).

\section{Participants}

The participant population $(\mathrm{N}=238)$ in all four trials were adolescents, with the mean age ranging from 16 to 18 years. The transition programmes that were evaluated differed in the types of chronic condition upon which they focused. Huang 2014 recruited patients with a range of chronic conditions that included cystic fibrosis, inflammatory bowel disease, and type $1 \mathrm{di}-$ abetes (T1DM). The other trials focused on patients with specific chronic conditions including; heart disease (Mackie 2014), T1DM (Steinbeck 2014), and spina bifida (Betz 2010). All four trials excluded patients who had developmental delay or cognitive impairment. These were small trials, including between 26 and 81 participants each.

\section{Setting}

In three studies, the patients were recruited from tertiary care hospital units and outpatient clinics (Huang 2014; Mackie 2014; Steinbeck 2014); Betz 2010 recruited from hospitals and support groups. In all studies, the interventions were delivered while participants were in the community and receiving outpatient care. Two trials were undertaken in the USA (Betz 2010; Huang 2014), one in Canada (Mackie 2014), and one in Australia (Steinbeck 2014).

\section{Description of intervention}

The four included RCTs evaluated interventions that focused on the patient, rather than targeting health professionals or systems. Betz 2010 evaluated a cognitive-behavioural programme delivered via a workshop to adolescents and their families; Huang 2014 evaluated a web-based and SMS-delivered skill-based intervention; Mackie 2014 evaluated an intervention delivered by an experienced cardiology nurse that involved a one-on-one meeting; and Steinbeck 2014 evaluated the use of three standardised telephone communications (over six months) from a transition co-ordinator following discharge from paediatric care, and paper and electronic (USB sticks) copies of information on services and health care for diabetes (Characteristics of included studies).

Three interventions sought to improve knowledge and self-management skills in preparation for transition to adult care (Betz 2010; Huang 2014; Mackie 2014). The intervention by Steinbeck 2014 was implemented post-discharge from paediatric care and sought to promote better use of adult diabetic services.

The components of the interventions, and the number and duration of the sessions also varied. The cognitive-behavioural programme, called the Transition Preparation Training (TPT), was delivered via a two-day weekend workshop and consisted of three modules (Day 1 was five hours long and contained modules 1 and 2, Day 2 was 4.5 hours long and covered module 3). The workshop assessed goals and dreams related to health, school work, community living, housing, recreation, and leisure. It also facilitated the creation of a comprehensive transition plan, with the identification of service needs, service referrals, and contact information. The information was reinforced with learning opportunities to practice strategies for obtaining services, and included role-playing, oneon-one interactions, coaching, audio-visual aids, internet, and reinforced and mentored learning. The treatment group had TPT alongside usual spina bifida care management; the control group received only usual care, though the details of 'usual spina bifida care management' was not described. The authors did not report who delivered the intervention (Betz 2010).

The web- and SMS-delivered technology program involved an eight-month management programme based on Bandura’s Social Cognitive Theory. The intervention targeted the self-management constructs of monitoring disease symptoms, responding to monitoring with appropriate treatments, and actively working with healthcare providers to manage care. For two months, subjects logged into a secure website weekly to receive theme-based materials outlining common disease management and communication skills, and lifestyle tips. Case studies were provided to increase us- 
ability. Tailored text messages and queries were delivered (three to five messages per week) to ensure that participants received and understood the intervention messages. After two months, website access was provided as a disease management and information resource. Weekly reminder text messages were also delivered to reinforce previously introduced concepts and skills. To facilitate patient-initiated communication, intervention group patients were given access to an automated SMS algorithm that provided disease management decision support and a healthcare team communications portal. Participants could activate the SMS to report health concerns. Controls received monthly messages via mail or email (participant preference) addressing general health issues. Diseasespecific information was provided as appropriate (for example, in the healthy nutrition module). Usual healthcare communication portals were available to patients in the control group. It was not clear who had designed or delivered the program (Huang 2014). The intervention evaluated by Mackie 2014 was one structured meeting with an experienced cardiology nurse, the duration of which was not described. The elements of the structured meeting included: discussion about transition and its importance, issues of confidentiality, issues related to their cardiac condition, complications, medication, details of important contact names, and an introduction to relevant websites. Case studies were used to address health behaviour and written materials were supplied. A 'MyHealth' passport was also created, including the name of their cardiac condition, previous cardiac interventions, name and purpose of medications, and if there was a need for endocarditis prophylaxis. Participants in the usual care group were variably provided verbal or written information, or both, by their cardiologist or cardiology clinic nurse, at the discretion of these providers.

The intervention evaluated by Steinbeck 2014 included the transition coordinator making the first adult diabetes service appointment and providing their contact details (this was also done for the participants in the usucal care group). The intervention group received adult diabetic services, directions and transport, useful websites, information relevant to personal diabetic health care, and a formal referral letter. This was followed by four standardised telephone communications at week one, and at three and six months to provide support, establish an understanding of the transition process, and discuss the participant's general well-being, life events, transition difficulties, and contact with their adult diabetic services. The duration of the calls varied, but their mean duration at months three and six was 8.5 minutes. At 12 months, a follow-up phone call was made to confirm transfer status (Steinbeck 2014).

None of the studies provided details of how the time of transfer for individual patients was decided.

\section{Outcomes}

Disease-specific patient outcomes and status were our primary outcome and were measured in two studies (Huang 2014; Steinbeck
2014). Huang 2014 used validated scales developed for each disease experienced by the participants, including: the Paediatric Ulcertaive Colitis Activity Index, Paediatric Crohn's Desease Activity index, Cystic Fibrosis Clinical Score, and the Diabetes Quality of Life Brief Clincial Inventory. None of the results from these measurement tools were reported or provided when the review authors requested them from the study authors. Steinbeck 2014 reported $\mathrm{HbA1c} \%$, IFCC $\mathrm{mmol} / \mathrm{mol}$.

Three studies reported on readiness for transition (Betz 2010; Huang 2014; Mackie 2014). Two studies used the Transition Readiness Assessment Questionnaire (TRAQ) scale (Huang 2014; Mackie 2014), and one study used the Patient Activation Measure (PAM) scale, the Community Life Skills Scale (CLSS) and the Denyes Self-Care Practice (DSCPI-90) (Betz 2010). One study reported the TRAQ score at baseline, but not at follow-up (Steinbeck 2014). The TRAQ questionnaire is a 29-item, two domain patient-reported assessment of health and health care self-management skills. The TRAQ uses a Likert scale, with possible scores ranging from one (low) to five (optimal). Mean self-management TRAQ score among adolescents with chronic health conditions is 3.01 (SD 1.02) and mean self-advocacy score is 3.67 (SD 0.77; Sawicki 2009).

The PAM scale uses a scale of $0-100$ representing functioning as an independent adult with a chronic disease. A PAM score of higher than 68.5 is equivalent to having the self-efficacy and confidence to take charge of one's own health and care and therefore would be ready for transition.

The CLSS is a 33 item tool focusing on six areas measuring various types of community skills, including transportation, support services, support involvement, interest and hobbies and regularity of organisation and routines, amounting to 28 items.

Two studies reported on disease knowledge (Huang 2014; Mackie 2014). Mackie 2014 used the MyHeart scale; Huang 2014 used the Test of Functional Health Literacy in Adults. The MyHeart scale was developed for use in the Mackie 2014 study and consists of seven questions; a higher score indicates a greater knowledge of the participant's heart condition. The DSCPI-90 is an 18-item questionnaire that measures both general health behaviours and specific self-care behaviours. Higher scores reflect a higher level of self-care abilities.

Two studies reported on well-being and quality of life (Betz 2010; Huang 2014). Betz 2010 used the Personal Adjustment and Role Skills Scale (PARS) III and Huang 2014 used the Pedatric Quality of Life Scale (PedsQL). The PARS III assesses the psychosocial adjustment of children and youth with special healthcare needs, without cognitive impairment. The tool contains 28 items measuring six areas of functioning associated with maladjustment; peer relations, dependency, hostility, productivity, anxiety-depression, and withdrawal.

One study measured patient-initiated healthcare communications by measuring messages to the communication portal, and phone conversations between participants and his or her healthcare team 
(Huang 2014).

One study measured healthcare resource use or costs and reported the number of diabetes-related hospitalisations in the previous 12 months (Steinbeck 2014).

\section{Intervention acceptability}

This was assessed by examining treatment adherence in all included studies.

\section{Excluded studies}

See the Characteristics of excluded studies table for a complete list of excluded studies with reasons.

\section{Risk of bias in included studies}

The risk of bias in the included studies is described in the 'Risk of bias' tables in the Characteristics of included studies tables and summarised in Figure 2 and Figure 3. 
Figure 2. Risk of bias summary: review authors' judgements about each risk of bias item for each included study.

\begin{tabular}{|c|c|c|c|c|c|c|c|c|}
\hline & 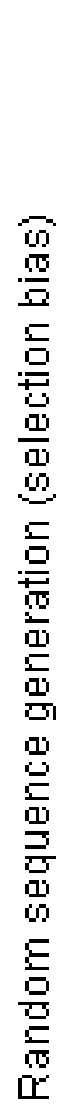 & 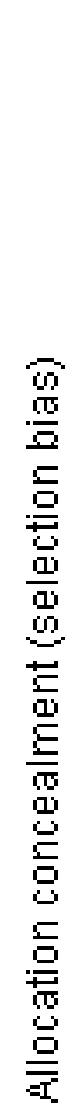 & 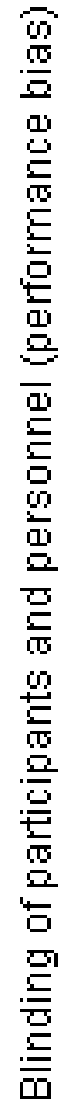 & 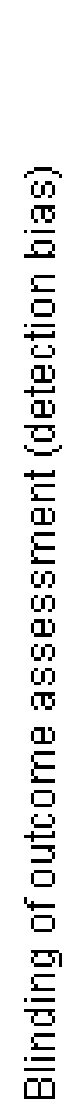 & 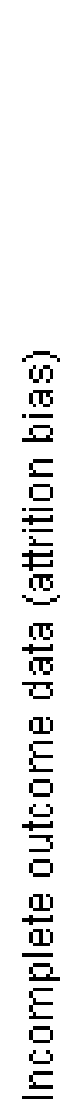 & 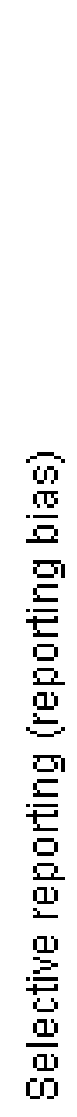 & 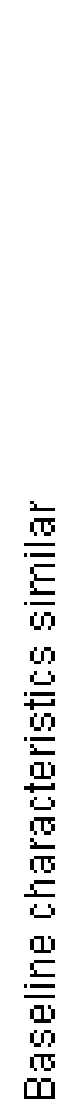 & 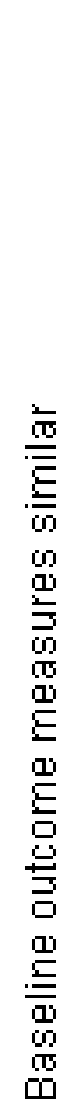 \\
\hline Betr 2010 & $?$ & $?$ & $?$ & & & $?$ & $?$ & $?$ \\
\hline Huang 2014 & \pm & + & & + & & $?$ & $?$ & $?$ \\
\hline Mackie 2014 & $?$ & $?$ & & & $?$ & & $?$ & $?$ \\
\hline Steinbeck 2014 & & & & $?$ & & & & \\
\hline
\end{tabular}


Figure 3. Risk of bias graph: review authors' judgements about each risk of bias item presented as percentages across all included studies.

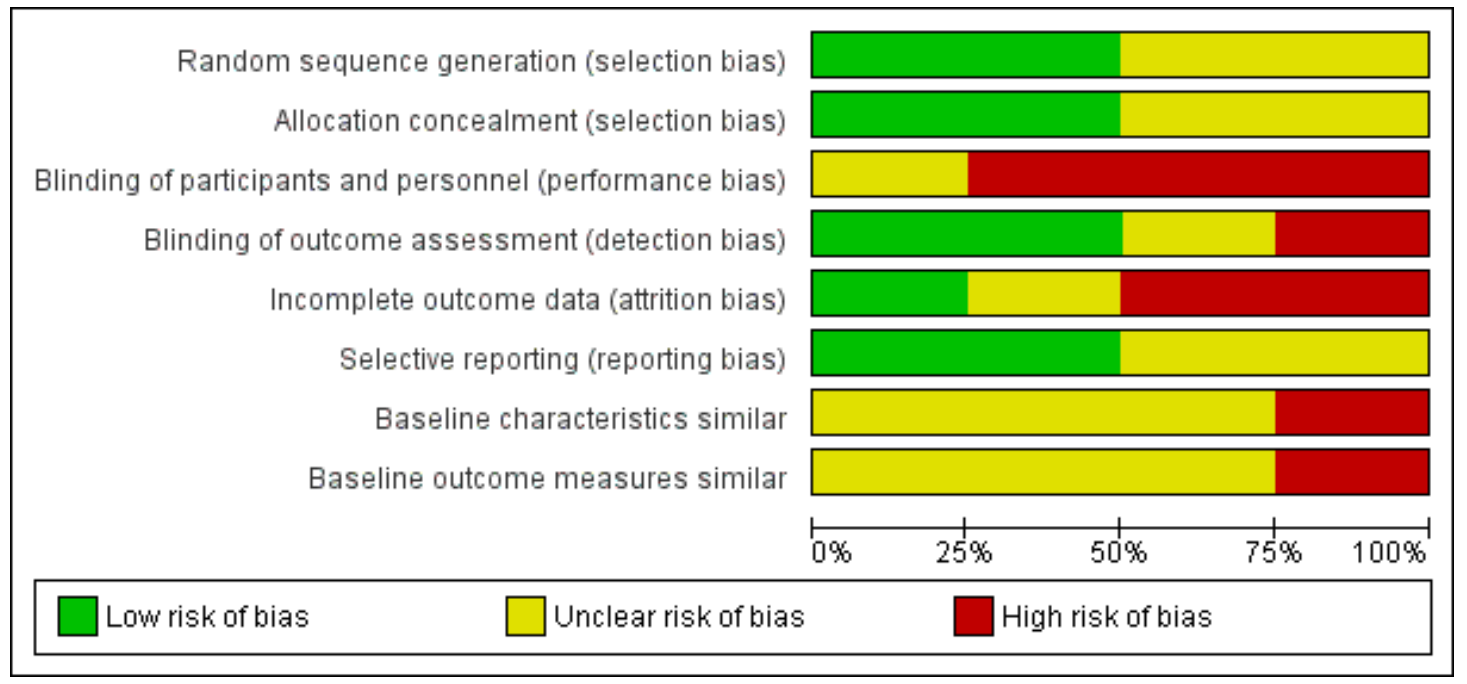

\section{Allocation}

The included studies were considered to be at low risk of selection bias. The method of randomisation was considered adequate in three studies (Huang 2014; Mackie 2014; Steinbeck 2014), and unclear in one (Betz 2010). The process of allocation concealment was not described in three of the studies (Betz 2010; Huang 2014; Steinbeck 2014,). One cluster-RCT used alternative allocation to intervention and control groups (Mackie 2014).

\section{Blinding}

Detection bias was judged as high in one study Betz 2010, at low risk in two studies (Huang 2014; Mackie 2014), and unclear in one study (Steinbeck 2014). In one study, the analysts were blind to participants' group allocation at the assessment of final outcomes (Huang 2014). Presence of performance bias was unclear in one study Betz 2010, and high in three (Huang 2014; Mackie 2014; Steinbeck 2014).

\section{Incomplete outcome data}

Two trials were considered at low risk for attrition bias (Huang 2014; Mackie 2014). Huang 2014 reported that $7.4 \%$ (6/81) and Mackie 2014 that $24.2 \%(16 / 66)$ were not included in the final analysis, with similar numbers missing in each group. In the Betz
2010 study, attrition was higher in the transitional-care group than in the control group (11/42 (26.2\%) versus $4 / 38(10.5 \%))$. Steinbeck 2014 reported that $8 / 26(30.8 \%)$ participants were lost to follow-up, 5/14 (35.7\%) from the intervention group and $3 /$ $12(25 \%)$ from the control group.

\section{Selective reporting}

There was no evidence of selective reporting of outcomes, but it was not possible to compare the study results with published protocols.

\section{Other potential sources of bias}

One study reported baseline differences for glycated haemoglobin (intervention 9.9\%, control 8.0\%; Steinbeck 2014).

\section{Effects of interventions}

\section{See: Summary of findings for the main comparison}

Data were reported for the following outcomes: disease-specific outcomes, readiness for transition, adherence and acceptability, health-related quality of life and well-being, knowledge of condition, healthcare use. There were no data reported on patient satisfaction, self-advocacy, transitional issues or unanticipated or adverse outcomes. 


\section{Primary Outcomes}

\section{Disease specific outcomes}

One study reported that the disease status of the treatment group did not change over the study period (no numerical data were provided; Huang 2014). One study found that glycated haemoglobin levels (HbA1c) were higher in the intervention group than in the control group (median 10.2\%; interquartile range (IQR) $8.8 \%$ to $13.2 \%$ versus median $8.3 \%$; IQR $7.7 \%$ to $8.7 \%$; $\mathrm{P}=0.01$ ). For people with diabetes, an HbA1c level of $48 \mathrm{mmol} / \mathrm{mol}(6.5 \%)$ is considered good control. However, the groups were not balanced at baseline; the intervention group had a higher baseline level of HbA1c (median 9.9\%; IQR 7.6\% to $10.6 \%$ versus median $8.0 \%$; IQR 7.2\% to $8.6 \%$; $\mathrm{P}=0.02$; Steinbeck 2014).

\section{Secondary Outcomes}

\section{Transitional readiness (Disease management and self- efficacy)}

Participant's readiness for transition was reported in two studies and measured using the TRAQ questionnaire at six to eight-month follow-ups (Huang 2014; Mackie 2014. In the Huang 2014 trial, which evaluated an SMS- and text-based technology programme, the mean difference (MD) was 0.20 (95\% CI -0.16 to 0.56$)$ and in the Mackie 2014 trial evaluating the nurse-led intervention, the MD was 0.43 (-0.09 to 0.95$)$. One study (Huang 2014) reported higher self-efficacy scores and confidence in managing their own health and health care in the intervention group at both twomonth (MD: $10 ; 95 \%$ CI 2.76 to 17.24 ) and eight-month followups (MD:10; 95\% CI 2.96 to 17.04 ).

Betz 2010 reported the difference in the extent to which participants lived independently and used community resources, assessed with the Community Life Skills Scale (CLSS); four-month followup (MD 0.77; CI -1.12 to 2.66).

\section{Patient satisfaction}

No studies measured this outcome.

\section{Treatment adherence and acceptability}

All of the studies reported the numbers of adolescents who were eligible to participate but declined. These were 21/154 (13.6\%), $15 / 118$ (12.7\%), 18/105 (17.1\%), and 474/500 (94.8\%) in Betz 2010; Huang 2014; Mackie 2014; and Steinbeck 2014 respectively. In two studies, the numbers of participants withdrawing from the trial was similar in both the intervention and control groups; 6/81 (7.4\%) in Huang 2014, and 6/66 (12.1\%) in Mackie 2014. In one study, the numbers that withdrew from the intervention group (11/42 (26.2\%)) was greater than those who withdrew from the control group (4/38 (10.5\%); Betz 2010). Seven of the participants who withdrew from the intervention group did so for reasons related to the nature of the intervention; the most common reason given was that they were unable to schedule attendance.

\section{Health-related quality of life and well-being}

One study reported the difference between the intervention and control groups in subjective well-being at four months (MD 1.29; 95\% CI -4.49 to 7.07), using the Personal Adjustment and Role Skills Scale (PARS III) tool (Betz 2010). One study reported no difference between groups in quality of life at eight months, using the Pediatric Quality of Life Scale (PedsQL); no outcome data reported; Huang 2014).

\section{Disease-related knowledge}

One study reported improved patient knowledge of their heart condition (using the MyHeart scale) for the intervention group at one and six months (MD at six months: 14.0; 95\% CI 2.67 to 25.33; Mackie 2014).

Betz 2010 reported little or no difference between the intervention and control groups in self-care practices at four months (MD -3.70; CI-11.34 to 3.94), using the Denyes Self-Care Practice Instrument (DSCPI - 90@).

\section{Self-advocacy skills}

No studies measured these outcomes.

\section{Improved documentation of transitional issues}

No studies measured these outcomes

\section{Unanticipated or adverse outcomes}

No studies measured these outcomes

\section{Healthcare resource use related to transition of care and cost data}

One study reported the number of participants who had transferred from a paediatric to an adult diabetic service. At follow-up, $11 / 14(79 \%)$ of the participants of the intervention group had transferred from a paediatric to an adult diabetic service compared with $12 / 12(100 \%)$ in the control group $(\mathrm{P}=0.20)$. The target number of attendance at diabetic clinics (three to four times annually) was met by five intervention participants and two control participants out of the nine in each group for whom this information was available. The time taken to transfer from paediatric to adult care was also measured, with a median of 15 weeks (IQR 8 to 19 ), compared with a median of 14 weeks (IQR 11 to 20) in the control group. The number of hospitalisations related to diabetes 
in the previous 12 months was $1 / 14(7.1 \%)$ in the intervention group and $3 / 12(25 \%)$ in the control group $(\mathrm{P}=0.6$; Steinbeck 2014).

\section{I SCUSSIO N}

\section{Summary of main results}

See: Summary of findings for the main comparison

We included four RCTs ( $\mathrm{N}=238$ participants) in this review. The certainty of the body of evidence from these studies is low. The four studies explored different types of interventions: transitionpreparation training (TPT) delivered in a two-day workshop for adolescents with spina bifida; a web- and SMS-based educational intervention for adolescents with a range of different conditions; a one-hour, nurse-led, one-on-one teaching session with the additional support of a 'health passport' for youth with heart disease; and a structured, comprehensive transition programme with a transition co-ordinator for adolescents with type 1 diabetes (Betz 2010; Huang 2014; Mackie 2014; Steinbeck 2014).

Transition interventions may lead to slight improvements in disease management and self-efficacy (transition readiness). Transition readiness is a term that refers to the process of building the capacity of adolescents and those involved in their care to prepare for, enter, continue, and complete transition. It involves multiple components, is measurable and potentially modifiable. Transition readiness measures have a range of clinical purposes, but in research, they allow the assessment of outcomes of an intervention and comparisons between groups. Disease management and self-efficacy were measured using various tools including: TRAQ, DSCPI-90C, and the PAM. Two studies evaluating the one-onone nurse-led intervention (Mackie 2014), and the technology based intervention (Huang 2014), suggest that these transition interventions may lead to slight improvements in readiness for transition, and chronic disease self-management measured at sixto eight-month follow-ups. Results using the TRAQ tool were: MD $0.20 ; 95 \%$ CI -0.16 to 0.56 (Huang 2014), MD 0.43; $95 \%$ CI -0.09 to 0.95 (TRAQ Self-management; Mackie 2014), MD 0.37; 95\% CI -0.06 to 0.80 (TRAQ Self-advocacy; Mackie 2014). Results using the PAM tool were: MD 10; 95\% CI 2.96 to 17.04 (Huang 2014). In contrast, transition-preparation training (TPT) delivered via a two-day workshop for patients with spina bifida did not lead to any difference in measures of self-care practice regarding general health behaviours, when measured using DSCPI90@ (Betz 2010).

One study evaluating a technology-based intervention (Huang 2014), and another evaluating a comprehensive transition programme (Steinbeck 2014), found that these interventions may lead to slightly more young people taking positive steps to initiate contact with health professionals themselves. (Relative risk: 4.87;
$95 \%$ CI 0.24 to 98.12 and $1.50 ; 95 \%$ CI 0.32 to 6.94 respectively).

Young people's knowledge of their disease was slightly improved with a nurse-led, one-on-one intervention to prepare young people for transition to an adult congenital heart programme (MD 14; 95\% CI 2.67 to 25.33; Mackie 2014)

Disease-specific outcome measures were reported in two studies; the transition interventions in these studies led to no little or no difference in outcomes. Huang 2014 reported measuring health status outcomes using validated tools including; Paediatric Ulcerative Colitis Activity Index, Paediatric Chron's Disease Activity Index, Forced Expiratory Volume (FEV) \%, diabetes glycohaemoglobin (HbA1c) \%. The authors reported finding little or no difference between treatment and control groups, however, the data were not reported or provided by the author. Steinbeck 2014 found that the clinical outcomes measured, including measures of diabetes control, were better in the control group. However, this difference may be due to differences in baseline values in which the HbA1c \% was higher in the control group. They found little or no difference in the use of adult services between the intervention and control groups or any difference in the numbers achieving the recommended number of clinic attendances annually. The study was limited in its power to identify differences due to the small number of participants $(\mathrm{N}=26)$. Steinbeck 2014), found that follow-up HbA1c in young people with type 1 diabetes mellitus increased by $1.2 \%$ for each percentage increase in baseline $\mathrm{HbAlc}$, independent of treatment group $(1.2 \%$; $95 \%$ CI 0.4 to $1.9 ; \mathrm{P}=$ $0.01)$.

Transition interventions may not lead to any difference in well-being or quality of life. Two studies measured well-being and quality of life using PARS III (Betz 2010), or the PedsQL tool (Huang 2014). Both the technology-based intervention (Huang 2014), and the two-day workshop for young people with spina bifida found little or no difference between intervention and control groups (MD 1.29; 95\% CI -4.49 to 7.07; Betz 2010). Huang 2014 did not report the data.

Little or no differences in rates of transfer from paediatric to adult diabetes services were found at 12-month follow-up in one small study $(\mathrm{N}=26)$ that compared a comprehensive transition process with standard practice (Steinbeck 2014).

There was also a higher drop-out rate of participants in the workshop-based intervention (Betz 2010), with scheduling being cited by five of those withdrawing as a barrier to participation. This may be an important factor to consider in the design of further transitional-care services. Participation and uptake was the same in both intervention and control groups for the one-on-one, single session with a cardiology nurse (Mackie 2014), and the web- and SMS text-based technology programme (Huang 2014).

One study reported the number of diabetes-related hospitalisations in the previous 12 months. Participation in a comprehensive transition programme may lead to slightly fewer disease-related hospital admissions (RR: $0.29 ; 95 \%$ CI 0.03 to 2.40 ; Steinbeck 


\section{Overall completeness and applicability of evidence}

The evidence to support the development of transitional-care services is at present, limited by the absence of rigorously evaluated interventions. We were only able to include four small studies that had recruited a total of 238 participants. The available evidence is drawn from a limited number of settings, with the studies conducted in the USA (Betz 2010; Huang 2014), Canada (Mackie 2014), and Australia (Steinbeck 2014), and it is unclear to what extent the results are relevant to other healthcare delivery settings. This review included four studies which looked at four different types of interventions. All targeted the individual adolescent; none targeted the healthcare professionals or the organisation of care. Thus, a limited range of potential models of transitional-care have been evaluated.

The risk of relying on this evidence base, is that interventions that are more readily evaluated and perhaps less complex, have a greater body of research evidence than more complex interventions that are potentially much more difficult to evaluate in an RCT design, but which might provide more significant outcomes. This may also reflect the difficulty in evaluating a complex intervention of this nature using randomised control designs (McDonagh 2006a; McDonagh 2010). This particular challenge is raised by McDonagh, et al, who conducted an in-depth, controlled study of a transitional-care intervention (McDonagh 2006; McDonagh 2010). She stated that for reasons of intervention complexity, the individual-centred and evolving nature of transitional care (within the UK at that time), and the multidisciplinary nature of transitional care, that a randomised trial was not considered ethical or possible.This review included four studies that looked at four different types of interventions: a technology-based intervention, a workshop-based intervention, a telephone-based intervention, and a nurse-led intervention. Each targeted the individual adolescent. Therefore, they only represented one type of intervention, and at present, there are many other models of transitional care that need to be evaluated and included in a systematic review before one can gain a complete understanding about the evidence in this area. The evidence is also very limited in terms of exploring the long term-effects of the interventions, as the follow-up of the included studies was relatively short ( 4 to 12 months). Transtional care plays a crucial role in preventing the deterioration that can occur in young peoples' health status once they transfer to adult health services. However, as only one study included clinical outcome data and the follow-up period was limited to 12 months, there is no evidence on the effectiveness of the interventions in preventing this deterioration in health status in the long-term.

The evidence presented in this review is also limited in its applicability. Whilst one of the studies targeted patients with a range of conditions, the other three studies focused on one condition only (Huang 2014). Therefore, the scope of the evidence, in terms of representing the many types of chronic health conditions that adolescents may experience is also limited. We did not identify studies that assessed the transfer of children into primary care. The included studies did not address how the interventions might impact differentially on disadvantaged groups.

\section{Quality of the evidence}

All four included studies were randomised controlled trials, and although the method of randomisation was described and judged to be adequate, the process of allocation concealment was not described in three of the studies. Only one study attempted blinding at outcome assessment. These limitations introduce a risk of selection and performance bias. As we were unable to pool data, we could not explore the presence of statistical heterogeneity. Assessing consistency among trials was not possible, as the four included studies were small (recruited only 238 participants in total), recruited different study populations, and evaluated different interventions. The short follow-up periods (ranging from 4 months to 12 months) also limited the quality of the evidence, providing inadequate data to determine either the full impact of the interventions or the sustainability of the outcomes. The certainty of the evidence was judged to be low, using the GRADE approach, and we judged that further research is very likely to have an important impact on our confidence in the estimate of effect and is likely to change the estimate.

\section{Potential biases in the review process}

We tried to avoid bias by having a skilled information scientist write and run the search strategy, and by not applying date or language restrictions. All citations were screened by at least two review authors, and at least two review authors extracted data and assessed the risk of bias of included studies.

\section{Agreements and disagreements with other studies or reviews}

Nine relevant reviews have been published. These include a review of transition services for adolescents with specific conditions including: diabetes (Fleming 2002), palliative care (Doug 2011), mental health (Paul 2014), and spina bifida (Binks 2007). Three reviews included studies where patients might have a range of special healthcare needs or disabilities (Bloom 2012; Crowley 2011; Forbes 2002). Two reviews synthesised qualitative evidence of patients perspectives (Fegran 2014; Lugasi 2011). The reviews all concluded that there was a weak evidence base to inform practice and a need for additional studies with strong research design. They drew on a range of study designs and as none included the studies from this review, there are few similarities in our findings. 
The results of this review are far more tentative and inconclusive regarding the benefits of interventions. It may be that the application of rigorous approaches to evaluation demonstrate the limited effectiveness seen with these interventions.

None of the studies included in this review were included in previous quantitative reviews; this reflects in part the dates of publication, but primarily the different thresholds for inclusion of quantitative study designs. All of the previous reviews highlighted the lack of rigorously evaluated interventions.

The effectiveness review by Crowley 2011, which explored transitional-care services for adolescents with a range of health conditions, included ten studies. None of the studies attempted a randomised design, and the authors highlighted the lack of methodologically rigorous studies as a limitation of the review. Previous reviews have also noted the paucity of robust evaluation of transition-care programmes. The Crowley 2011 review described three broad categories of intervention directed at the patient (education programmes, skills training); staff (named transition co-ordinator, joint clinics run by paediatric and adult physicians); and service delivery (separate young adult clinics, after-hours phone support, enhanced follow-up). This review was only able to describe rigorous evaluation of interventions that had targeted the patients. A finding reported in the Crowley 2011 study that was consistent with this review, was evidence to support the use of disease-specific educational programmes, which aim to improve young people's knowledge of their condition and self-management skills.

\section{A U THORS' CONCLUSIONS}

\section{Implications for practice}

The interventions tested in the studies included in this review were very different, so It was not possible to draw conclusions from pooled estimate of effects. There were positive outcomes in the patients' knowledge of their condition following a nurse-led, oneon-one intervention. It was impossible to elicit from this study whether extending this intervention would increase its effectiveness, or to what extent the outcome would be reproducible in other contexts. The study did not find any improvement in the participants' transition-readiness scores (as assessed by the TRAQ), which may indicate that simply increasing disease knowledge is insufficient to improve their readiness for transition. It may also indicate the difficulty in using measurement scales to capture complex attitudes and behaviours.

The results also suggested that interventions that use technology may have a beneficial effect on participants' self-efficacy and confidence in managing their own health and health care. Once again, improvements in this measurement were not reflected in a significant improvement in TRAQ scores.
Limited evidence suggested that workshop-based interventions did not lead to beneficial outcomes or have a good uptake in patients with spina bifida.

Research evidence that had been methodologically designed to determine treatment effectiveness and met the rigour needed to be included in this review of effectiveness was very limited. The four included studies only explored interventions for patients with a limited range of conditions. There were no studies that evaluated the effects of interventions for other patient groups, such as those with mental health needs, patients who had had transplants, and patients with terminal illnesses. The included studies also excluded patients with learning difficulties. These are also a group of particularly vulnerable patients for whom needs at transition may be additionally complex.

\section{Implications for research}

Only four studies met the inclusion criteria for this review, and although there was a wealth of papers concerned with this subject, none had used robust study designs to test transitional services. If policy-makers and healthcare organisations wish to promote evidence-based transitional care, they must ensure that the studies testing these are well designed. We outline key aspects of study design to be considered, below.

- Randomised controlled trials (RCTs), the 'gold standard' study design should be used where possible

- Controlled before- and after-studies (CBAs) should include two intervention and two control sites

- Interrupted time-series (ITSs) should have at least three data points before and three data points after the intervention to permit a time series analysis

It is important to note that there are some problems with designing research to test transitional-care interventions. One issue surrounds the idea of 'usual care', which is usually used as the control for a comparison study. Usual care in relation to transitionalcare services is wide-ranging and inconsistent. Additional barriers to the development of robust evaluation studies are the diversity of the conditions experienced by this patient population and the relatively small numbers of young people involved. There is also a question of transferability and generalisability of findings, with interventions not necessarily having the same effect in different healthcare contexts. There needs to be further research that is more relevant to local contexts. In addition, there need to be studies that explore other types of interventions, and seek to determine which elements of an intervention contribute to treatment effectiveness. For example, future research needs to explore interventions that target healthcare professionals and the organisation of health care. Clinical outcomes need to be measured where relevant and possible, alongside robust measurements of readiness for transition and 
qualitative experiences of adolescents, their families, and healthcare professionals.

A challenge for conducting robust study designs is the need for evaluation studies that measure long-term health outcomes. Their impact on long-term health behaviours and health outcomes are critical to understanding the value of interventions designed to improve transitional care. None of the included studies evaluated long-term health outcomes, but their measurement should be incorporated in future research.

Although this review considered transitional-care services for patients who may have any chronic condition, it is likely that transitional-care services and their effectiveness will be strongly influenced by contextual factors related to the nature of the patient's condition. Therefore, the transitional-care services for patients with mental health needs may not be the same as those for patients who have had transplant surgery.

A particular challenge highlighted in one of the included studies was the difficulty in recruiting adequate numbers of adolescents for the trial in order to show a difference in clinical outcomes (Steinbeck 2014). They suggest that multi-centred trials might assist in addressing this particular challenge in future studies.

Crowley 2011 suggested established approaches to service development and evaluation in adult medicine that may have particular relevance during the transition period, including for example, the use of individual care co-ordinators or case managers. In their review of transition to adult health services of adolescents with mental health needs, Paul 2014 notes that there have been no studies that evaluated shared management framework interventions, such as transition teams and co-ordinators, employed by Child and Adolescent Mental Health Services, to direct transitional care, assist with training mental health staff, or evaluate and manage transition clinics.

We intend to conduct a review of qualitative evidence and included these findings in the update of this review. This will provide insights into the experiences of patients, professionals, and families receiving transitional services, thereby informing our understanding of what elements of transitional care are effective and why.

\section{ACKNOW LEDGEMENTS}

We wish to thank the EPOC group for advising on methodology and for developing the search strategy, and the peer reviewers for their comments: Antoine Rachas, Nizar Mahlaoui, Orlaith Burke (statistician), Signe Flottorp , Luke Vale, Gerd Flodgren, Julia Worswick, Sasha Shepperd.

Additionally, National Institute for Health Research (NIHR), via Cochrane Infrastructure funding to the Effective Practice and Organisation of Care (EPOC) Group. The views and opinions expressed therein are those of the authors and do not necessarily reflect those of the Systematic Reviews Programme, NIHR, National Health Service (NHS) or the Department of Health.

\section{R E F E R E N C E S}

\section{References to studies included in this review}

Betz 2010 \{published data only\}

Betz CL, Smith K, Macias K. Testing the transition preparation training program: A randomized controlled trial. International Journal of Child and Adolescent Health 2010;3(4):595-607.

Huang 2014 \{published data only\}

Huang JS, Terrones L, Tompane T, Dillon L, Pain M, Gottschalk M, et al. Preparing Adolescents With Chronic Disease for Transition to Adult Care: A Technology Program. Pediatrics 2014;133:e1639-46.

Mackie 2014 \{published data only\}

Mackie AS, Islam S, Magill-Evans J, Rankin KN, Robert C, Schuh M, et al. Healthcare transition for youth with heart disease: a clinical trial. Heart 2014;100:1113-8.

Steinbeck 2014 \{published data only\} Steinbeck KS, Shrewsbury VA, Harvey V, Mikler K, Donaghue KC, Craig ME, et al. A pilot randomized controlled trial of a post-discharge program to support emerging adults with type 1 diabetes mellitus transition from pediatric to adult care. Pediatric Diabetes 2014;16(8): $1-6$.

\section{References to studies excluded from this review}

Anderson 1999 \{published data only\}

Anderson BJ, Brackett J, Ho J, Laffel LM. An office-based intervention to maintain parent-adolescent teamwork in diabetes management. Impact on parent involvement, family conflict, and subsequent glycemic control. Diabetes Care 1999;5:713-21.

Anderson 2009 \{published data only\} Anderson S, Wynn L, Osarogiagbon R, Adams-Graves P, McHugh L, Steele V, et al. Teenager Transition Tour Program for young adults with sickle cell disease. American Journal of Hematology 2009;84(8):E69-70.

Balcazar 1995 \{published data only\}

Balcazar Fabricio E, Keys Christopher B, Garate-Serafini Juana. Learning to recruit assistance to attain transition goals: A program for adjudicated youth with disabilities. Remedial and Special Education 1995;16(4):237-46. 
Caravalho 2000 \{published data only\}

Caravalho JY, Saylor CR. Continuum of care: An evaluation of a nurse case-managed program for children with diabetes. Pediatric Nursing 2000;26(3):296-300.

Gregory 2011 \{published data only\}

Gregory JW, Robling M, Bennert K, Channon S, Cohen D, Crowne E, et al. Development and evaluation by a cluster randomised trial of a psychosocial intervention in children and teenagers experiencing diabetes: the DEPICTED study. Health Technology Assessment (Winchester, England) 2011;15 (29):1-202.

Hoek 2011 \{published data only\}

Hoek W, Marko M, Fogel J, Schuurmans J, Gladstone T, Bradford N, et al. Randomized controlled trial of primary care physician motivational interviewing versus brief advice to engage adolescents with an Internet-based depression prevention intervention: 6-month outcomes and predictors of improvement. Translational Research: The Journal of Laboratory \& Clinical Medicine 2011;158(6):315-25.

Husted 2011 \{published data only\}

Husted GR, Thorsteinsson B, Esbensen BA, Hommel E, Zoffmann V. Improving glycaemic control and life skills in adolescents with type 1 diabetes: a randomised, controlled intervention study using the Guided Self-DeterminationYoung method in triads of adolescents, parents and health care providers integrated into routine paediatric outpatient clinics. BMC Pediatrics 2011;11:55.

Jessup 2011 \{published data only\}

Jessup M, Hauser J, Cameron-Tucker H, Cummings E, Turner P, Blizzard L, et al. Facilitating self-Management in adolescents and adults with cystic fibrosis: A pilot study. Pediatric Pulmonology 2011;46:405-6.

LaDonna 2008 \{published data only\} LaDonna KA, Koopman WJ, Viana R, Campbell C, Schulz $\mathrm{V}$, Venance SL. A pilot study to determine the transition needs of adolescents and adults with Duchenne Muscular Dystrophy; 2008 June 18-20; Victoria British Columbia. Canadian Journal of Neuroscience Nursing. Ottawa: Canadian Association of Neuroscience Nurses, 2008; Vol. 30 , issue $1: 17$.

Landback 2009 \{published data only\} Landback J, Prochaska M, Ellis J, Dmochowska K, Kuwabara SA, Gladstone T, et al. From prototype to product: development of a primary care/Internet based depression prevention intervention for adolescents (CATCH-IT). Community Mental Health Journal 2009;45 (5):349-54.

Mason 2011 \{published data only\}

Mason M, Pate P, Drapkin M, Sozinho K. Motivational interviewing integrated with social network counseling for female adolescents: a randomized pilot study in urban primary care. Journal of Substance Abuse Treatment 2011;2: $148-55$.

Mulvaney 2010 \{published data only\} Mulvaney SA, Rothman RL, Wallston KA, Lybarger C, Dietrich MS. An internet-based program to improve self- management in adolescents with type 1 diabetes. Diabetes Care 2010;33(3):602-4.

Mulvaney 2011 \{published data only\}

Mulvaney SA, Rothman RL, Osborn CY, Lybarger C, Dietrich MS, Wallston KA. Self-management problem solving for adolescents with type 1 diabetes: intervention processes associated with an Internet program. Patient Education \& Counseling 2011;85(2):140-2.

Raghavan 2009 \{published data only\}

Raghavan R, Newell R, Waseem F, Small N. A randomized controlled trial of a specialist liaison worker model for young people with intellectual disabilities with challenging behaviour and mental health needs. Journal of Applied Research in Intellectual Disabilities 2009;22(3):256-63.

Styron 2006 \{published data only\} Styron TH, O'Connell M, Smalley W, Rau D, Shahar G, Sells $\mathrm{D}$, et al. Troubled youth in transition: An evaluation of Connecticut's special services for individuals aging out of adolescent mental health programs. Children and Youth Services Review 2006;28(9):1088-101.

Viana 2007 \{published data only\}

Viana R, LaDonna K, Koopman W, Campbell C, Schulz V, Venance S. Pilot study to determine the transition needs of adolescents and adults with Duchenne muscular dystrophy. Neuromuscular Disorders 2007;17(9-10):864-5.

\section{References to studies awaiting assessment}

Puri 2009 \{published data only\}

Puri SC, Tennant A, Clarke MA. Does an Integrated Needs Assessment (INA) improve social adjustment during transition from paediatric to adult services. European Journal of Paediatric Neurology 2009;13:S126.

Shipp 2011 \{published data only\}

Shipp AR, Siragusa A, Crews B, Scott P. Journey to independence: Transitioning to adult cystic fibrosis care. Pediatric Pulmonology 2011;46:405.

\section{Additional references}

AAP 2002

American Academy of Family Physicians and American College of Physicians-American Society of Internal Medicine. A consensus statement on health care transitions for young adults with special health care needs. Pediatrics 2002;110:1304-6.

Binks 2007

Binks JA, Barden WS, Burke TA, Young NL. What do we really know about the transition to adult-centered health care? A focus on cerebral palsy and spina bifida. Archives of Physical Medicine and Rehabilitation 2007;88(8):1064-73.

Bloom 2012

Bloom SR, Kuhlthau K, Van Cleave J, Knapp AA, Newacheck P, Perrin JM. Health care transition for youth with special health care needs. Journal of Adolscent Health 2012;51:213-9. 
Blum 1993

Blum RW, Garell D, Hodgman CH, Jorissen TW, Okinow NA, Orr DP, et al. Transition from child-centered to adult health-care systems for adolescents with chronic conditions. A position paper of the Society for Adolescent Medicine. Journal of Adolescent Health 1993;14(7):570-6.

\section{Busse 2007}

Busse FP, Hiermann P, Galler A, Stumvoll M, Wiessner T, Kiess W, et al. Evaluation of patients' opinion and metabolic control after transfer of young adults with type 1 diabetes from a paediatric diabetes clinic to adult care. Hormone Research in Paediatrics 2007;67(3):132-8.

\section{CPS 2006}

Canadian Paediatric Society. Care of adolescents with chronic conditions. Paediatrics Child Health 2006;11(1): 43-8.

\section{CQC 2014}

Care Quality Commission. From the Pond into the Sea (Children's transition to adult health services). Available from: https://www.cqc.org.uk/sites/default/files/ CQC' Transition\%20Report 'Summary 'lores.pdf June 2014.

\section{Crowley 2011}

Crowley R, Wolfe I, Lock K, McKee M. Improving the transition between paediatric and adult healthcare: a systematic review. Archives of disease in childhood 2011;96 (6):548-53.

\section{CSCI 2007}

Commission for Social Care Inspection. Growing up matters: Better transition planning for young people with complex needs. Available from: http:// www.yorkshirefutures.com/what works/growing-mattersbetter-transition-planning-young-people-complex-needs. London: Commission for Social Care Inspection, 2007.

\section{Cystic Fibrosis Trust 2008}

Cystic Fibrosis Foundation. Patient Registry Annual Data Report. Cystic Fibrosis Foundation, Bethesda, MD 2008.

\section{DH 1999}

Department of Health. Convention on the Rights of the Child. Second report to the UN Committee on the Rights of the Child by the United Kingdom. Available from: http: //www.dh.gov.uk/en/Publicationsandstatistics/Publications/ PublicationsPolicyAndGuidance/DH`4008238 1999.

\section{DH 2003}

Department of Health. Getting the right start: National service framework for children. Standard for hospital services. Available from: www.doh.gov.uk/nsf/children/ gettingtherightstart 2003.

\section{DH 2004}

Department of Health, Department for Education and Skills. National service framework for children, young people and maternity services. Available from: http:// www.dh.gov.uk/en/Publicationsandstatistics/Publications/ PublicationsPolicyAndGuidance/DH`4089101.

Department of Health, 2004.

\section{DH 2006}

Department of Health, Child Health and Maternity Services. Transition: getting it right for young people. Improving the transition of young people with long-term conditions from children's to adult health services. Available from: http:// www.dh.gov.uk/en/Publicationsandstatistics/Publications/ PublicationsPolicyAndGuidance/DH· 4132145. London: Department of Health Publications, 2006.

\section{DH 2008}

Department of Health. Under their Skins: Tackling the health of the teenage nation 2007.. On the state of Public Health. Annual report of the Chief Medical Officer July 2008.

\section{DH 2010}

Department for Children, Schools and Families \& Department of Health/Children's Mental Health Teams. Keeping children and young people in mind - the Government's full response to the independent review of CAMHS. Available from: http:// www.dh.gov.uk/en/Publicationsandstatistics/Publications/ PublicationsPolicyAndGuidance/DH`110785 January 2010

DH 2013

Department of Health. Improving Children and Young People's Health Outcomes: a system wide response. Available from: http://bit.ly/10PSvjR February 2013.

\section{Dick 2015}

Dick B, Ferguson BJ. Health for the world's adolescents: A second chance in the second decade. Journal of Adolescent Health 2015;56(1):3-6.

Dodge 2007

Dodge JA, Lewis PA, Stanton M, Wilsher J. Cystic fibrosis mortality and survival in the UK: 1947-2003. European Respiratory Journal 2007;29(3):522-6.

\section{Doug 2011}

Doug M, Adi Y, Williams J, Paul M, Kelly D, Petchey R, et al. Transition to adult services for children and young people with palliative care needs: a systematic review. $B M J$ Support Palliative Care 2011;1(2):167-73.

\section{Egger 1997}

Egger M, Smith GC, Schneider M, Minder C. Bias in metaanalysis detected by a simple, graphical test. BMJ 1997; 315:629-34.

\section{Fegran 2014}

Fegran L, Hall EO, Uhrenfeldt L, Aagaard H, Ludvigsen MS. Adolescents' and young adults' transition experiences when transferring from paediatric to adult care: a qualitative metasynthesis. International Journal of Nursing Studies 2014;51(1):123-35.

Fleming 2002

Fleming E, Carter B, Gillibrand W. The transition of adolescents with diabetes from the children's health care service into the adult health care service: a review of the literature. Journal of Clinical Nursing 2002;11(5):560-7. 
Forbes 2002

Forbes A, While A, Ullman R, Lewis S, Mathes L, Griffiths. A multi-method review to identify components of practice which may promote continuity in the transition from child to adult care for young people with chronic illness or disability. Report for the National Co-ordinating Centre for NHS Service Delivery and Organisation R\&D (NCCSDO) 2002:1-109.

Gleeson 2012

Gleeson H, Turner G. Transition to adult services. Archives of Disease in Childhood 2012;97(3):86-92.

\section{Gosden 2010}

Gosden C, Edge JA, Holt RI, James J, Turner B, Winocour $\mathrm{P}$, et al. The fifth UK paediatric diabetes services survey: meeting guidelines and recommendations?. Archives of Disease in Childhood 2010;95(10):837-40.

\section{Guyatt 2008}

Guyatt GH, Oxman AD, Vist G, Kunz R, Falck-Ytter Y, Alonso-Coello P, et al for the GRADE Working Group. GRADE: An emerging consensus on rating quality of evidence and strength of recommendations. BMJ 2008;336 (7650):924-6.

\section{Hagell 2015}

Hagell A. Building a picture of health from data. Journal of Family Health 2015;25(5):32-3.

\section{Higgins 2003}

Higgins JPT, Thompson SG, Deeks JJ, Altman DG. Measuring inconsistency in meta-analysis. BMJ 2003;327: 557-60.

\section{Higgins 2008}

Higgins JPT, Altman DG (editors). Chapter 8: Assessing risk of bias in included studies. In: Higgins JPT, Green $S$ (editors). Cochrane Handbook for Systematic Reviews of Interventions Version 5.0.1 [updated September 2008]. The Cochrane Collaboration 2008. Available from: www.cochrane-handbook.org.

\section{Kaufman 2006}

Kaufman M. Role of adolescent development in the transition process. Progress in Transplantation 2006;16(4): 286-90.

\section{Kennedy 2008}

Kennedy A, Sawyer S. Transition from pediatric to adult services: are we getting it right?. Current Opinion in Pediatrics 2008;20(4):403-9.

\section{Kipps 2002}

Kipps S, Bahu T, Ong K, Ackland FM, Brown RS, Fox CT, et al. Current methods of transfer of young people with Type 1 diabetes to adult services. Diabetic Medicine 2002; 19(8):649-54

\section{Kirk 2014}

Kirk S, Fraser C. Hospice support and the transition to adult services and adulthood for young people with lifelimiting conditions and their families: A qualitative study. Palliative Medicine 2014;28(4):342-52.

\section{Latzman 2011}

Latzman RD, Majumdar S, Bigelow C, Elkin TD, Smith MG, Megason GC, et al. Transitioning to adult care among adolescents with sickle cell disease: a transitioning clinic based on patient and caregiver concerns and needs. International Journal of Child Health and Adolescent Health 2011;3(4):537-45.

\section{Lotstein 2005}

Lotstein DS, McPherson M, Strickland B, Newacheck PW. Transition planning for youth with special health care needs: results from the National Survey of Children with Special Health Care Needs. Pediatrics 2005;115(6):1562-8.

\section{Lotstein 2013}

Lotstein DS, Seid M, Klingensmith G, Case D, Lawrence JM, Pihoker C, et al. Transition from pediatric to adult care for youth diagnosed with type 1 diabetes in adolescence. Pediatrics 2013;131(4):e1062-70.

\section{Lugasi 2011}

Lugasi T, Achille M, Stevenson M. Patients' perspective on factors that facilitate transition from child-centered to adultcentered health care: a theory integrated metasummary of quantitative and qualitative studies. Journal of Adolescent Health 2011;48(5):429-40.

McDonagh 2004

McDonagh JE, Southwood TR, Shaw KL. Unmet education and training needs of rheumatology health professionals in adolescent health and transitional care. Rheumatology (Oxford) 2004;43(1462-0324 (Print), 14620324 (Linking), 6):737-43.

\section{McDonagh 2006}

McDonagh JE, Minnaar G, Kelly K, O'Connor D, Shaw $\mathrm{KL}$. Unmet education and training needs in adolescent health of health professionals in a UK children's hospital. Acta Paediatrica 2006;95(0803-5253 (Print), 0803-5253 (Linking), 6):715-9.

\section{McDonagh 2006a}

McDonagh JE, Viner RM. Lost in transition? Between paediatric and adult services. BMJ 2006;332(7539):435-6.

\section{McDonagh 2010}

McDonagh JE, Kelly DA. The challenges and opportunities for transitional care research. Pediatric Transplantation 2010;14(6):688-700.

\section{McManus 2008}

McManus MA, Fox H, O'Connor K, Chapman T, MacKinnon J. Pediatric perspectives and practices on transitioning adolescents with special needs to adult health care.. National Alliance to Advance Adolescent Health 2008; Factsheet 6:1-6.

\section{Moher 2009}

Moher D, Liberati A, Tetzlaff J, Altman DG, The PRISMA Group. Preferred Reporting Items for Systematic Reviews and Meta-Analyses: The PRISMA Statement. PLoS Med 2009;6(6):e1000097. [DOI: 10.1371/ journal.pmed1000097] 


\section{Moons 2009}

Moons P, Hilderson D, Van Deyk K. Congenital cardiovascular nursing: preparing for the next decade. Cardiology in the Young 2009;19(Suppl 2):106-11.

\section{Moons 2010}

Moons P, Meijboom FJ. Healthcare provision for adults with congenital heart disease in Europe: a review. Current Opinion in Pediatrics 2010;22(5):573-8.

Nakhla 2009

Nakhla M, Daneman D, To T, Paradis G, Guttmann A. Transition to adult care for youths with diabetes mellitus: findings from a Universal Health Care System. Pediatrics 2009;124(6):e1134-41.

Paul 2014

Paul M, Street C, Wheeler N, Singh SP. Transition to adult services for young people with mental health needs: A systematic review. Clinical Child Psychology and Psychiatry 2014;Jul;20(3):1-22.

\section{RCN 2008}

Royal College of Nursing. Lost in transition: Moving young people between child and adult health services. Available from: http://www.rcn.org.uk/ ' data/assets/pdf file/0010/ 157879/003227.pdf. Royal College of Nursing, 2008.

RCN Adolescent Health 2004

Royal College of Nursing Adolescent Health Forum. Adolescent transition care. Available from: http:/ /www.rcn.org.uk/“ ' data/assets/pdf file/0011/78617/ 002313.pdf. Royal College of Nursing, 2004.

\section{RCPCH 2003}

Royal College of Paediatrics and Child Health. Bridging the gaps: health care for adolescents. Available from: http:// www.rcpch.ac.uk/sites/default/files/bridging the' gaps.pdf. London: RCPCH, 2003.

\section{RCPE 2008}

Royal College of Physicians of Edinburgh Transition Steering Group. Think Transition: Developing the essential link between paediatric and adult care. Available from: http://www.rcpe.ac.uk/clinical-standards/documents/ transition.pdf. Edinburgh: Royal College of Phsicians of Edinburgh, 2008.

\section{Reference Manager 2010 [Computer program]}

Thompson Reuters. Reference Manager Professional Edition Version 12. Version Version 12. London: Thomson ISI ResearchSoft, 2010.

Reid 2004

Reid GJ, Irvine MJ, McCrindle BW, Sananes R, Ritvo PG, Siu SC, et al. Prevalence and correlates of successful transfer from pediatric to adult health care among a cohort of young adults with complex congenital heart defects. Pediatrics March 2004;113(3):197-205.

\section{Sawicki 2009}

Sawicki GS, Lukens-Bull K, Yin X, Demars N, Huang IC, Livingood W, et al. Measuring the transition readiness of youth with special healthcare needs: Validation of the
TRAQ - transition readiness assessment questionnaire. Journal of Pediatric Psychology 2009;36(2):160-71.

Sawyer 2007

Sawyer SM, Drew S, Yeo MS, Britto MT. Adolescents with a chronic condition: challenges living, challenges treating. Lancet 2007;369 (9571):1481-9.

Sawyer 2012

Sawyer SM, Afifi RA, Bearinger LH, Blakemore SJ, Dick B, Ezeh AC, et al. Adolescence: a foundation for future health. Lancet 2012;379(9826):1630-40.

\section{Scal 2005}

Scal P, Ireland M. Addressing transition to adult health care for adolescents with special health care needs. Pediatrics 2005;115(6):1607-12.

\section{Shaw 2004}

Shaw KL, Southwood TR, McDonagh JE. Developing a programme of transitional care for adolescents with juvenile idiopathic arthritis: results of a postal survey. Rheumatology 2004; 43(2):211-9

Snow 2009

Snow V, Beck D, Budnitz T, Miller DC, Potter J, Wears RL, et al. Transitions of care consensus policy statement: American College of Physicians, Society of General Internal Medicine, Society of Hospital Medicine, American Geriatrics Society, American College of Emergency Physicians, and Society for Academic Emergency Medicine. Journal of Hospital Medicine 2009;4(6):364-70.

Suris 2009

Suris JC, Akre C, Rutishauser C. How adult specialists deal with the principles of a successful transition. Journal of Adolescent Health 2009;45(6):551-5.

US Department of Health and Human Services 2002 American Academy of Pediatrics, American Academy of Family Physicians, and American College of PhysiciansAmerican Society of Internal Medicine. A consensus statement on health care transitions for young adults with special health care needs. Pediatrics 2002;3:1304-6.

Viner 1999

Viner R. Transition from paediatric to adult care. Bridging the gaps or passing the buck?. Archives of Disease in Childhood 1999;81(3):271-5.

\section{Watson 2005}

Watson AR. Problems and pitfalls of transition from paediatric to adult renal care. Pediatric Nephrology 2005;20 (2):113-7.

\section{Watson 2011}

Watson R, Parr JR, Joyce C, May C, Le Couteur AS. Models of transitional care for young people with complex health needs: a scoping review. Child: care, health and development 2011;37(6):780-91.

\section{While 1996}

While A, Citrone C, Cornish J. A study of the needs and provisions for families caring for children with life-limiting incurable disorders. London: King's College London, Department of Nursing Studies, 1996. [B00101JAZB] 


\section{While 2004}

While A, Forbes A, Ullman R, Lewis S, Mathes L, Griffiths P. Good practices that address continuity during transition from child to adult care: synthesis of the evidence. Child: Care, Health and Development 2004;30(5):439-52.

\section{WHO/UNAIDS (2015)}

WHO/UNAIDS. Global standards for quality healthcare services for adolescents: a guide to implement a standards-driven approach to improve the quality of healthcare services for adolescents. Geneva, World Health Organization 2015.

\section{Yeung 2008}

Yeung E, Kay J, Roosevelt GE, Brandon M, Yetman AT.
Lapse of care as a predictor for morbidity in adults with congenital heart disease. International Journal of Cardiology 2008;125(1):62-5.

\section{References to other published versions of this review}

\section{Campbell 2012}

Campbell F, O'Neill PM, While A, McDonagh J.

Interventions to improve transition of care for adolescents

from paediatric services to adult services (Protocol)..

Cochrane Database of Systematic Reviews 2012;4:DOI:

10.1002/14651858.CD009794.

* Indicates the major publication for the study 


\section{CHARACTERISTICS OF STUDIES}

\section{Characteristics of included studies [ordered by study ID]}

\section{Betz 2010}

$\begin{array}{ll}\text { Methods } & \text { Study design: RCT } \\ \text { Purpose: To examine whether a cognitive-behavioural programme of Transition Prepa- } & \text { ration Training (TPT) in combination with spina bifida management (usual care) leads } \\ \text { to improved transition } & \text { Inclusion criteria: Participants between } 14 \text { and } 18 \text { years old, with a diagnosis of spina } \\ \text { bifida, English speaking, no history of intellectual disability or mental illness, and willing } \\ \text { to complete the questionnaires } \\ \text { Exclusion criteria: Patients with intellectual disability or mental illness. Unwilling to } \\ \text { complete questionnaire }\end{array}$

Participants

Total N: 80 randomised; Intervention: 42; Control:38

Lost to follow up: (11/42 (26.2\%) lost to follow-up in intervention group, 4/38 (10. $5 \%)$ lost to follow-up in control group); 65 analysed

Setting of recruitment: Hospitals and support group, USA

Method of recruitment: Convenience in spina bifida clinics in hospitals; invitation letters sent to support group

Patient characteristics:

Clinical condition: Spina bifida

Mean age: 16 years (SD 1.4).

Gender: female 39/80 (60\%); male N=27/80 (40\%),

Ethnicity: white 4 (6\%), Latino 58 (90\%), Multiethnic 2 3\%), Asian 1 (1\%)

Comparability at baseline: No tests for similarity reported, and no statement given

Interventions

Setting of intervention: unclear

Professionals delivering intervention: 'trainer'

Staff training: Not detailed

Targeted at: Adolescent patients with spina bifida

Intervention modality: face-to-face delivered workshop

Description of the intervention:

Module 1 (2 sessions) - assessment of goals and dreams related to health, school work, community living, housing, recreation and leisure;

Module 2 ( 2 sessions) creating comprehensive transition plan - including identification of service needs, service referrals and contact information;

Module 3 ( 4 sessions) learning opportunities to practice strategies for obtaining services: Role-playing, 1-to-1, coaching, reinforced learning, audio visual aids, Internet and mentored learning

Control: usual care, spina bifida management

Duration of intervention: 2 days

Frequency: one

Reimbursement received: \$25 to youth; \$25 retail card to parent

- Subjective well-being, assessed with the Psychosocial Adjustment and Role Skills Scale III (PARS III); 
- Role mastery, assessed with the Community Life Skills Scale (CLSS);

- Self-care practice, assessed with the: Denyes Self-Care Practice Instrument (DSCPI - 90C)

Follow up: 4 months

Notes

Limitations reported by authors: The one month time frame for the study was insufficient to effect the change that youth identified in their transition plan. Developing and being able to test interventions is methodologically challenging. Limited empirically sound tools to use in the assessment of interventions. From 154 youth who were assessed for eligibility, 80 youth with spina bifida meeting inclusion criteria were randomised. Unclear how many adolescents were invited to participate, and how many of these that declined participation. Short follow-up period

\section{Risk of bias}

\begin{tabular}{l|ll}
\hline Bias & Authors judgement & Support for judgement \\
\hline $\begin{array}{l}\text { Random sequence generation (selection } \\
\text { bias) }\end{array}$ & Unclear risk & $\begin{array}{l}\text { Not described in detail but it was stratified } \\
\text { by gender. }\end{array}$ \\
\hline $\begin{array}{l}\text { Allocation concealment (selection bias) } \\
\text { Blinding of participants and personnel } \\
\text { (performance bias) } \\
\text { All outcomes }\end{array}$ & Unclear risk & Not described. \\
\hline
\end{tabular}

Self-reported outcomes and participants were aware of their allocation
Blinding of outcome assessment (detection High risk bias)

All outcomes

Incomplete outcome data (attrition bias) High risk All outcomes

Selective reporting (reporting bias)

Unclear risk

Unclear risk

Unclear risk

Baseline outcome measures similar
The attrition was higher in transitional-care group

$11 / 42(26.2 \%)$ lost to follow-up in intervention group, $4 / 38(10,5 \%)$ lost to followup in control group

Reported as described in the methods section, but no protocol available. Additional reporting of sub-scales

No comparison between groups reported in the review. The mean age of those in the experimental group was higher (16.2 years) compared with the control group (15.7 years)
Not tested for similarity, appear comparable 


\section{Methods}

Study design: RCT

Purpose: To evaluate whether a generic, internet- and mobile phone-delivered disease management intervention would improve disease management, self-efficacy, and communication outcomes in adolescents with chronic diseases

Inclusion criteria: Adolescents, aged 12 to 22 years with diverse chronic illnesses

Exclusion criteria: Patients with cognitive impairments.
Participants
Total N: 81 randomised, Intervention: $\mathrm{N}=40$; Control: $\mathrm{N}=41$

Lost to follow up: Intervention:2/38 (5.3\%) ; Usual care:4/37 (9.8\%); 75 in the analyses Setting of recruitment: Tertiary care paediatric academic medical centre. USA

Method of recruitment: Recruited (Oct 2010 to March 2011) from a tertiary care paediatric academic medical centre serving -1 million youth. Informed consent and assent were obtained

Patient characteristics:

Clinical condition: Cystic Fibrosis, Inflammatory Bowel Disease and Type 1 Diabetes

Mean age: 17 years, range 12 to 20 years

Gender: female 44/81 (54\%); male 37/81 (46\%)

Baseline measures/screening: Disease category: Chron's disease Intervention 11, control

12; Ulcerative colitis Intervention 5, control 5; Cystic Fibrosis intervention 6, control 7; Type 1 Diabetes intervention 17, control 17

Disease Duration, median and IQR: Intervention 4 yrs (3 to 9 yrs), Control 6 years (2 to 10 years);

Paediatric Ulcerative Colitis Activity Index: Intervention 3 (IQR0-21), Control 0 (010)

Paediatric Chron's Disease Activity Index: Intervention 5 (IQR 5-10), Control 10 (IQR 1-20)

Baseline predicted forced expiratory volume in 1 second by percentage $\left(\mathrm{FEV}_{1} \%\right)$ : Intervention 87 (IQR69-94), control 81 (IQR 72-98);

Type 1 Diabetes glycohaemoglobin, \%: Intervention 8.2 (7.0 to 9.2), Control 8.6 (7.9 to 9.5 )

Comparability at baseline: No significant ethnic or gender differences
Setting of intervention: Based in a tertiary care paediatric academic setting. Professional delivering the intervention not described

Method of delivery: Intervention delivered on the Internet but details of how it was developed were not provided. short message service (SMS) algorithm linked to clinical team

Staff training: Not described, Internet-based intervention.

Targeted at: Adolescent patients.

Intervention modality: Web-based and text-delivered disease management and skillbased intervention

Description of intervention: An 8-month technology-based disease management intervention (MD2Me) based on Bandura's social cognitive theory. MD2Me recipients received a 2-month intensive web-based and text-delivered disease management and skillbased intervention followed by a 6-month review period. Recipeints also had access to a texting algorithm for disease assessment and healthcare team contact. Targetted: selfmanagement in disease monitoring, responding to monitoring with appropriate treatments and working with healthcare providers to manage care. Intervention delivered on the internet but details of how it was developed were not provided. SMS algorithm linked 
to clinical team. The intervention targeted the self-management constructs of monitoring disease symptoms, responding to monitoring with appropriate treatments, and actively working with healthcare providers to manage care. For 2 months, subjects were asked to $\log$ in to a secure website weekly to receive theme-based materials that outlined common disease management and communication skills, and lifestyle tips. Disease-specific case studies were provided to increase usability. Tailored SMS messages and queries were delivered (3 to 5 messages/week) to ensure that participants received and understood intervention messages. After 2 months, website access was provided as a disease management and information resource. Weekly reminder SMS messages were also delivered to reinforced previously introduced concepts and skills. To facilitate patient-initiated communication, the MD2ME recipients were given access to an automated SMS algorithm that provided disease management decision support and a healthcare team communications portal. This allowed participants to report health concerns. According to level of urgency, these were relayed to the healthcare team for intervention

Duration of intervention: Not detailed.

Frequency: Not detailed.

Reimbursement received: None.

Controls: Controls received monthly messages via mail or e-mail (participant preference) addressing general health issues. Disease-specific information was provided as appropriate (e.g. in the healthy nutrition module). Usual healthcare communication portals were available to controls

Outcomes

- Disease status, assessed with specific disease scales including the Pediatric Ulcerative Colititis Activity Index, Pediatric Crohn's Disease Activity Index, Cycstic Fibrosis Clinical Score, The Diabestes Quality of Life Brief Clinical Inventory, functional performance and quality of life.

- Health Literacy assessment tool: Test of Functional Health Literacy in Adults

- Global Health Status assessment tool: Karnofsky Performance Scale and the Pediatric Quality of Life Scale (PedsQL)

- Disease Management and Self-efficacy assessment tool: Transition REadiness Assessment Questionnaire (TRAQ)

- Patient-initiated healthcare communications: Frequency of patient-initialed communications was recorded over the study period.

Follow up: 2 and 8 months

Limitations reported by authors: "Relatively small sample size, single institution recruitment and specific patient populations studied. A potential confounder may have been the increased frequency of intervention interactions in the intervention group (weekly) compared with the control (monthly) group. The relatively short duration of the intervention and follow-up period likely limited our ability to affect disease and functional status."

\section{Risk of bias}

\begin{tabular}{ll} 
Bias Authors' judgement \\
\hline
\end{tabular}

\section{Support for judgement}

Random sequence generation (selection Low risk bias)
Random block assignment stratified by disease and generated by statistician occurred after baseline visit 


\section{Huang 2014 (Continued)}

\begin{tabular}{|c|c|c|}
\hline Allocation concealment (selection bias) & Low risk & $\begin{array}{l}\text { Inclusion was not dependent on group al- } \\
\text { location. Random block assignment strati- } \\
\text { fied by disease and generated by statistician } \\
\text { occurred after baseline visit }\end{array}$ \\
\hline $\begin{array}{l}\text { Blinding of participants and personnel } \\
\text { (performance bias) } \\
\text { All outcomes }\end{array}$ & High risk & $\begin{array}{l}\text { The nature of the intervention means that } \\
\text { those receiving the intervention and those } \\
\text { delivering it cannot be blind to group as- } \\
\text { signment }\end{array}$ \\
\hline $\begin{array}{l}\text { Blinding of outcome assessment (detection } \\
\text { bias) } \\
\text { All outcomes }\end{array}$ & Low risk & $\begin{array}{l}\text { Participants' disease self-management and } \\
\text { health-related self-efficacy were assessed at } \\
\text { study visits at a clinical research office by } \\
\text { measurement staff blinded to group assign- } \\
\text { ment }\end{array}$ \\
\hline $\begin{array}{l}\text { Incomplete outcome data (attrition bias) } \\
\text { All outcomes }\end{array}$ & Low risk & $\begin{array}{l}\text { Intention-to-treat used, all loss-to-follow- } \\
\text { up reported }\end{array}$ \\
\hline Selective reporting (reporting bias) & Unclear risk & $\begin{array}{l}\text { Outcome data not reported for clinical } \\
\text { measures }\end{array}$ \\
\hline Baseline characteristics similar & Unclear risk & $\begin{array}{l}\text { No ethnic or gender differences, stratified } \\
\text { by disease }\end{array}$ \\
\hline Baseline outcome measures similar & Unclear risk & $\begin{array}{l}\text { Baseline health literacy, disease manage- } \\
\text { ment and health-related self-efficacy were } \\
\text { similar between groups }\end{array}$ \\
\hline
\end{tabular}

Mackie 2014

Methods

Participants
Study design: RCT

Purpose: Determine the impact of a transition intervention on improving knowledge and self-management skills in youth with heart disease

Inclusion criteria: adolescents 15 to 17 year old with heart disease, attending a tertiary care cardiology clinic at a children's hospital

Exclusion criteria: heart transplant patients and those with developmental delay (where parent thought it would preclude them from taking part)

Total N: 66 allocated, Intervention: $\mathrm{N}=32$; Control: $\mathrm{N}=34$

Lost to follow-up: 16; 50 analysed (study reports that intention-to-treat analysis performed and none excluded from analyses)

Setting of recruitment: Tertiary care cardiology clinic at a children's hospital, Canada Method of recruitment: Not described

Patient characteristics:

Clinical condition:: Moderate or complex congenital heart disease or cardiomyopathy

Stage of transition: 15 to 17 year olds attending a tertiary care cardiology clinic at a children's hospital 
Mackie 2014

\begin{tabular}{|c|c|}
\hline & $\begin{array}{l}\text { Mean age: } 16.5 \text { (SD 1) } \\
\text { Gender: female } 19 / 58(33 \%) \text {; male } 39 / 78(77 \%) \\
\text { Comparability at baseline: No test for similarity reported. It appears that there were more } \\
\text { patients on medication at enrolment in the usual care group (15) compared with the } \\
\text { intervention group (10). Baseline scores for outcome measures were similar }\end{array}$ \\
\hline Interventions & $\begin{array}{l}\text { Setting of intervention: Private room near outpatients, alongside usual clinic appoint- } \\
\text { ment } \\
\text { Professionals delivering intervention: Experienced cardiology nurses } \\
\text { Staff training: Intervention-facilitation training and fidelity assurance } \\
\text { Targeted at: patients } \\
\text { Intervention modality: Structured meeting with nurse, including development of 'My- } \\
\text { Health' passport, disease-knowledge, health contacts information, adolescent issues dis- } \\
\text { cussion } \\
\text { Duration of intervention: } 1 \text { hour - mean duration } 68 \text { minutes (SD =18) } \\
\text { Frequency: one off session } \\
\text { Reimbursement received: none } \\
\text { Control: Usual care, not standardised. }\end{array}$ \\
\hline Outcomes & $\begin{array}{l}\text { Primary outcomes: } \\
\text { - Transition readiness (assessed with the TRAQ tool) } \\
\text { - Disease knowledge (assessed with the Knowledge of the heart condition } \\
\text { assessment tool: MyHeart scale) } \\
\text { Disease specific outcomes: none } \\
\text { Follow up: } 1 \text { and } 6 \text { months }\end{array}$ \\
\hline Notes & $\begin{array}{l}\text { Limitations reported by authors: } \\
\text { Single centre study, interventions delivered by a single nurse. Relied on self-report. } \\
\text { Short follow-up period. Long-term follow-up and attendance in an adult clinic were not } \\
\text { assessed. Developing skills of participants to interact with healthcare providers was not } \\
\text { part of the interventions }\end{array}$ \\
\hline
\end{tabular}

Risk of bias

\begin{tabular}{|c|c|c|}
\hline Bias & Authors' judgement & Support for judgement \\
\hline $\begin{array}{l}\text { Random sequence generation (selection } \\
\text { bias) }\end{array}$ & Unclear risk & $\begin{array}{l}\text { Inadequate method of randomisation, par- } \\
\text { ticipants were systematically allocated to ei- } \\
\text { ther a transition intervention or usual care } \\
\text { depending on their week of attendance in } \\
\text { the cardiology clinic }\end{array}$ \\
\hline Allocation concealment (selection bias) & Unclear risk & not described. \\
\hline $\begin{array}{l}\text { Blinding of participants and personnel } \\
\text { (performance bias) } \\
\text { All outcomes }\end{array}$ & High risk & $\begin{array}{l}\text { Paricipants and personnel delivering the in- } \\
\text { tervention were not blind to group assign- } \\
\text { ment }\end{array}$ \\
\hline
\end{tabular}

Transition of care for adolescents from paediatric services to adult health services (Review) 
Blinding of outcome assessment (detection Low risk

Outcome assessment was blind.

bias)

All outcomes

Incomplete outcome data (attrition bias) Unclear risk All outcomes

16 patients were not included in final analyses, 8 from the intervention group and 8 from the control group

\begin{tabular}{|c|c|c|}
\hline Selective reporting (reporting bias) & Low risk & no evidence of selective reporting \\
\hline Baseline characteristics similar & Unclear risk & $\begin{array}{l}\text { No test of similarity described, it would ap- } \\
\text { pear that there were more females in the } \\
\text { usual care group }(17 / 27(55 \%)) \text { compared } \\
\text { with the intervention group }(11 / 31(41 \%) \\
) \text {. A higher number in the usual care groups } \\
\text { also appeared to be on medication at en- } \\
\text { rolment }(15 / 31(48 \%)) \text { compared with the } \\
\text { intervention group }(10 / 27(37 \%))\end{array}$ \\
\hline
\end{tabular}

No test of similarity described, it would appear that at baseline, the self-management, self-advocacy and MyHeart scores were higher in the usual care group

Steinbeck 2014

Methods

Participants
Study design: RCT

Purpose: To compare the efficacy of a structured comprehensive transition programme (CTP) , implemented post-discharge from paediatric care, with standard clinical practice (SCP) over 12 months

Inclusion criteria: Participants had type 1 diabetes mellitus (T1DM), were $\geq 16$ years of age, and were attending outpatient clinics at two university teaching hospitals in Australia. Identified by their diabetologist as ready to transition

Exclusion criteria: Intellectual disability, lack of facility in English, transfer to the dedicated young adult diabetes service in an adjacent adult hospital

\section{Total N: 26}

Setting of recruitment: Attending outpatient clinic at university teaching hospital Method of recruitment: Participants were recruited at the last paediatric diabetes service visit. Young people and a parent or guardian (if the young person was $<18 \mathrm{yr}$ ) provided written consent to participate

Patient characteristics: HbA1c \% between groups. CTP: 9.9\%; SCP: 8.0\%; P = 0.02

Global self worth: CTP med 3.8 (IQR 2.9 to 3.9); SCP med 3.0 (2.8 to 3.8)

$\geq 1$ diabetes-related hospitalisation in past 12 months: CTP 3/14; SCP $2 / 12$

Clinical condition: Type 1 diabetes mellitis (T1DM)

Stage of transition: Post-discharge from paediatric services

Mean age: Age range 17.3 to 18.8 years

Gender: 14/26 (53.8\%) female; $12 / 26$ (46\%) male 
Steinbeck 2014 (Continued)

Comparability at baseline: no, levels of $\mathrm{HbA} 1 \mathrm{c} \%$ were higher in the intervention group (9.9\%) compared with the control group $(8.0 \%)$

Interventions

Setting of intervention: Participants were being cared for by adult specialist diabetes services as outpatients

Professionals delivering intervention: transition co-ordinator

Staff training: none reported

Targeted at: adolescents with T1DM transitioning from paediatric to adult health services Intervention modality: Structured transition protocol where the transition coordinator provided the young person with a hard and soft copy of their contact details, the adult services details, websites of useful services and information, personal diabetes health care information using a standardized template (with input from the young person) and a formal referral letter. The 'transition co-ordinator' provided standardised telephone communication support at week one (duration $\leq 6 \mathrm{~min}$ ), 3 and 6 months (mean duration 8.5 mins) and 12 months

Week1: aim was to ensure participants understood the transition process

Months 3 and 6: communication support concerned participants general well-being, life events, transition difficulties and contact with their adult diabetes service. The transition co-ordinator did not provide specific diabetes management advice

Duration of intervention: week one: $\leq 6$-minute telephone conversation, Month 3 and 6, mean duration 8.5 minutes (range 2 to 20 minutes)

Frequency:

Reimbursement received: none

Control: Standard care, the transition co-ordinator made the first adult diabetes service appointment for participants in both arms. The basic features included in the standard care included:1) decision made by paediatric diabetologist together with the patient and family on where and when they should transfer. No decision making tree involved. 2) referral letter provided; 3) no further information or support provided post-discharge. As part of the study, control participants were briefly contacted by the trial co-ordinator at 6 months to confirm transfer status

Outcomes

Primary outcomes:

- Transfer from paediatric to adult diabetes service occurred: CTP: $11 / 14(79 \%)$; SCP: $12 / 12(100 \%)(P=0.2)$

- Retention in original adult service referred to: CTP: $9 / 11$ (82\%); SCP: $(10 / 12$ $(83 \%)(\mathrm{P}=1.0)$

- Time taken to transfer from paediatric to adult care (weeks) CTP: med 15 (IQR 8 to 19), SCP: med 14 (IQR 11 to 20) $(\mathrm{P}=0.7)$

- Change in global self-worth Baseline: CTP: med 3.8 (IQR 2.9 to 3.9) ( $\mathrm{N}=13$ ); SCP: med 3.0 (IQR 2.8 to 3.8) $(\mathrm{N}=8)$; CTP: med 0 (IQR -0.8 to 0.1$)(\mathrm{N}=9)$; SCP: med -0.3 (IQR -0.9 to 0.1$)(\mathrm{N}=5)$; Score $1=$ low self-worth; Score 4 = high self-worth Disease specific outcomes:

- HbA1c (\%) at follow-up: CTP: median 10.2 (IQR 8.8 to 13.2 ); SCP: median 8.3 (7.7 to 8.7$)(\mathrm{P}=0.01)$

- service visits per annum (data from adult services for 9 participants in each arm. CTP: med 3 (IQR 2 to 5) ( $\mathrm{N}=$ 9); SCP: med 2 (IQR 1 to 4); $\mathrm{N}=9$; $\mathrm{P}=0.4$. (Australian guidelines recommend that T1DM patients are reviewed 3 to 4 times annually)

- $\geq 1$ diabetes related hospitalisation in past 12 months:CTP: $1(\mathrm{~N}=9)$; SCP: $3(\mathrm{~N}$ 
Steinbeck 2014 (Continued)

= 9) $(\mathrm{P}=0.6)$

- IFCC mmol/mol: CTP: med 88 (IQR 73 to 121) ( $\mathrm{N}=9$ ); SCP: med 67 (IQR 61 to 72) $(\mathrm{N}=9)$

- Development of new microvascular complications:CTP: 2 (low range microalbuminuria); SCP: 1 (non-proliferative diabetic retinopathy)

Follow up: 12 months

Notes

Limitations reported by authors:

The study was limited by a poor recruitment rate and the loss to follow-up of 8/26 participants. The sample size of 60 needed to detect an absolute minimum difference in adult service attendance rates was not achieved. Insufficient follow-up for transitionalcare setting

\section{Risk of bias}

\begin{tabular}{|c|c|c|}
\hline Bias & Authors' judgement & Support for judgement \\
\hline $\begin{array}{l}\text { Random sequence generation (selection } \\
\text { bias) }\end{array}$ & Low risk & Computer-generated four block design \\
\hline Allocation concealment (selection bias) & Low risk & opaque, sealed enveloped \\
\hline $\begin{array}{l}\text { Blinding of participants and personnel } \\
\text { (performance bias) } \\
\text { All outcomes }\end{array}$ & High risk & participants were not blinded \\
\hline $\begin{array}{l}\text { Blinding of outcome assessment (detection } \\
\text { bias) } \\
\text { All outcomes }\end{array}$ & Unclear risk & inadequate data \\
\hline $\begin{array}{l}\text { Incomplete outcome data (attrition bias) } \\
\text { All outcomes }\end{array}$ & High risk & $\begin{array}{l}\text { Only outcome data available for } 9 \text { in each } \\
\text { group. } 8 / 26 \text { lost to follow-up }\end{array}$ \\
\hline Selective reporting (reporting bias) & Low risk & no evidence of selective reporting \\
\hline Baseline characteristics similar & High risk & $\begin{array}{l}\text { No. HbA1c levels were significantly differ- } \\
\text { ent at baseline, with a higher percentage in } \\
\text { the intervention group (median } 9.9 \text { (IQR } \\
7.6 \text { to } 10.6) \text { ) and control group (median } 8 \text {. } \\
0 \text { (IQR } 7.2 \text { to } 8.6 \text { ) }\end{array}$ \\
\hline Baseline outcome measures similar & High risk & $\begin{array}{l}\text { No, HbAlc levels were significantly differ- } \\
\text { ent at baseline, with a higher percentage in } \\
\text { the intervention group (median } 9.9 \text { (IQR } \\
7.6 \text { to } 10.6 \text { ) ) and control group (median } 8 \text {. } \\
0 \text { (IQR } 7.2 \text { to } 8.6 \text { ) }\end{array}$ \\
\hline
\end{tabular}


Characteristics of excluded studies [ordered by study ID]

\begin{tabular}{|c|c|}
\hline Study & Reason for exclusion \\
\hline Anderson 1999 & Not about transition between child and adult services \\
\hline Anderson 2009 & Not about transition between child and adult services - adolescent care \\
\hline Balcazar 1995 & Not about transition between child and adult services - residential care and education \\
\hline Caravalho 2000 & Not about transition between child and adult services - self-management training \\
\hline Gregory 2011 & Not about transition between child and adult services \\
\hline Hoek 2011 & Not about transition between child and adult services \\
\hline Husted 2011 & Not about transition between child and adult services - improving life skills in paediatric clinics \\
\hline Jessup 2011 & Not about transition between child and adult services - self-management \\
\hline LaDonna 2008 & Not about transition between child and adult services - same title as Viana 2007 \\
\hline Landback 2009 & Not about transition between child and adult services \\
\hline Mason 2011 & Not about transition between child and adult services - adolescent care \\
\hline Mulvaney 2010 & Not about transition between child and adult services - adolescent care \\
\hline Mulvaney 2011 & Not about transition between child and adult services \\
\hline Raghavan 2009 & Not about transition between child and adult services \\
\hline Styron 2006 & Not about transition between child and adult services - independent living in the community \\
\hline Viana 2007 & Not about transition between child and adult services - same title as LaDonna 2008 \\
\hline
\end{tabular}

Characteristics of studies awaiting assessment [ordered by study ID]

Puri 2009

\begin{tabular}{ll}
\hline Methods & Pilot RCT study \\
\hline Participants & Young people with special educational needs in Year 11 to 12 \\
\hline Interventions & Holistic integrated needs assessment to identify met and unmet needs \\
\hline Outcomes & $\begin{array}{l}\text { A significant reduction in the level of perceived stress and self-reported well-being }(\mathrm{P}=0.18) \text { in caregivers was } \\
\text { observed, but these could not be attributed to the intervention, } \mathrm{P}=0.31 \text { and } \mathrm{P}=0.66 \text { respectively }\end{array}$ \\
\hline $\begin{array}{l}\text { Transition of care for adolescents from paediatric services to adult health services (Review) } \\
\text { Copyright } \odot \mathbf{2 0 1 6} \text { The Cochrane Collaboration. Published by John Wiley \& Sons, Ltd. }\end{array}$
\end{tabular}


Puri 2009 (Continued) $\begin{array}{ll}\text { Notes } & \text { Poster abstract, contacted author - poster sent, not enough data. Also looks like it is council rather than health services } \\ \text { based (but not clear). Full paper not published }\end{array}$

\section{Shipp 2011}

Methods Could not retrieve this data.

Participants Could not retrieve this data.

Interventions Could not retrieve this data.

Outcomes Could not retrieve this data.

Notes Poster abstract. Tried to contact authors but were unsuccessful. Could not retrieve this data 
DATA AND ANALYSES

Comparison 1. Transtional care versus usual care

\begin{tabular}{|c|c|c|c|c|}
\hline Outcome or subgroup title & $\begin{array}{l}\text { No. of } \\
\text { studies }\end{array}$ & $\begin{array}{c}\text { No. of } \\
\text { participants }\end{array}$ & Statistical method & Effect size \\
\hline 1 PARS III & 1 & & Mean Difference (IV, Fixed, 95\% CI) & Totals not selected \\
\hline $\begin{array}{l}2 \text { Denyes Self-Care Practice } \\
\text { Instrument (DSCPI - 90@) }\end{array}$ & 1 & & Mean Difference (IV, Fixed, 95\% CI) & Totals not selected \\
\hline $\begin{array}{l}3 \text { Community Life Skills Scale } \\
\text { (CLSS) }\end{array}$ & 1 & & Mean Difference (IV, Fixed, 95\% CI) & Totals not selected \\
\hline $\begin{array}{l}4 \text { Transition Readiness Assessment } \\
\text { Questionnaire (TRAQ). }\end{array}$ & 1 & & Mean Difference (IV, Fixed, 95\% CI) & Totals not selected \\
\hline 5 TRAQ (self-management) & 1 & & Mean Difference (IV, Fixed, 95\% CI) & Subtotals only \\
\hline 6 TRAQ (Self-advocacy) & 1 & & Mean Difference (IV, Fixed, 95\% CI) & Totals not selected \\
\hline 6.16 months follow up & 1 & & Mean Difference (IV, Fixed, 95\% CI) & $0.0[0.0,0.0]$ \\
\hline $\begin{array}{l}7 \text { Health-related self-efficacy } \\
\text { (PAM) }\end{array}$ & 1 & & Mean Difference (IV, Random, 95\% CI) & Totals not selected \\
\hline 7.12 months follow up & 1 & & Mean Difference (IV, Random, 95\% CI) & $0.0[0.0,0.0]$ \\
\hline 7.28 months follow up & 1 & & Mean Difference (IV, Random, 95\% CI) & $0.0[0.0,0.0]$ \\
\hline 8 Patient initiated communications & 2 & & Risk Ratio (M-H, Fixed, 95\% CI) & Subtotals only \\
\hline 9 MyHeart & 1 & & Mean Difference (IV, Fixed, 95\% CI) & Totals not selected \\
\hline 9.11 month follow-up & 1 & & Mean Difference (IV, Fixed, 95\% CI) & $0.0[0.0,0.0]$ \\
\hline 9.26 months follow-up & 1 & & Mean Difference (IV, Fixed, 95\% CI) & $0.0[0.0,0.0]$ \\
\hline 10 TRAQ (Self-advocacy) & 1 & & Mean Difference (IV, Fixed, 95\% CI) & Subtotals only \\
\hline $\begin{array}{l}11 \text { Transfer from child to } \\
\text { adolescent health services }\end{array}$ & 1 & & Risk Ratio (M-H, Fixed, 95\% CI) & Subtotals only \\
\hline $\begin{array}{l}12 \text { diabetes related hospitalizations } \\
\text { in previous } 12 \text { months }\end{array}$ & 1 & & Risk Ratio (M-H, Fixed, 95\% CI) & Subtotals only \\
\hline
\end{tabular}

\section{Analysis I.I. Comparison I Transtional care versus usual care, Outcome I PARS III.}

Review: Transition of care for adolescents from paediatric services to adult health services

Comparison: I Transtional care versus usual care

Outcome: | PARS |||

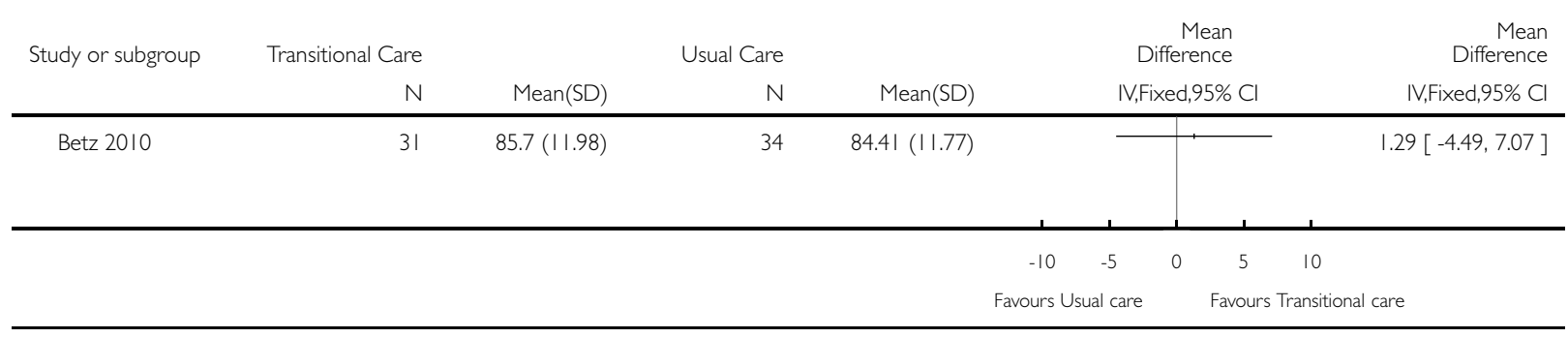

Transition of care for adolescents from paediatric services to adult health services (Review)

Copyright @ 2016 The Cochrane Collaboration. Published by John Wiley \& Sons, Ltd. 


\section{Analysis I.2. Comparison I Transtional care versus usual care, Outcome 2 Denyes Self-Care Practice}

Instrument (DSCPI - 90@).

Review: Transition of care for adolescents from paediatric services to adult health services

Comparison: | Transtional care versus usual care

Outcome: 2 Denyes Self-Care Practice Instrument (DSCPI - 90 )

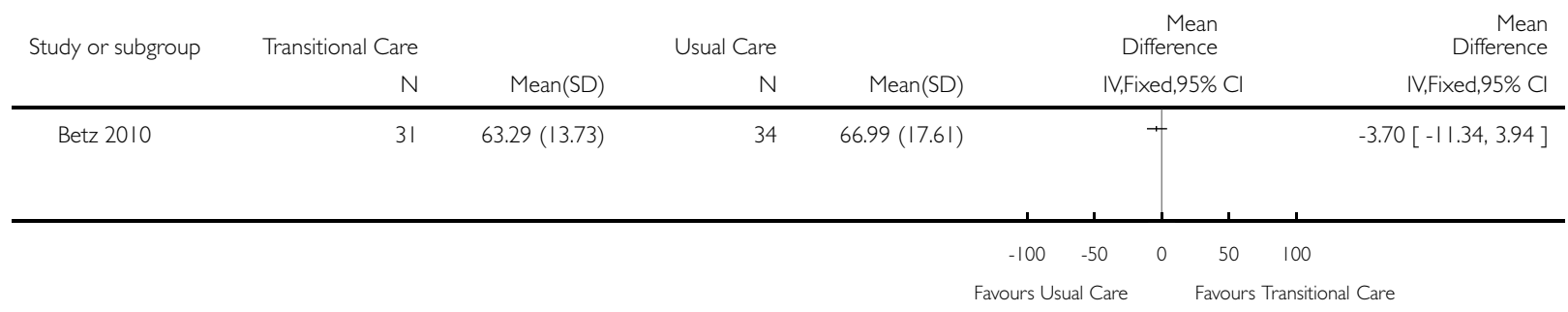

\section{Analysis I.3. Comparison I Transtional care versus usual care, Outcome 3 Community Life Skills Scale} (CLSS).

Review: Transition of care for adolescents from paediatric services to adult health services

Comparison: I Transtional care versus usual care

Outcome: 3 Community Life Skills Scale (CLSS)

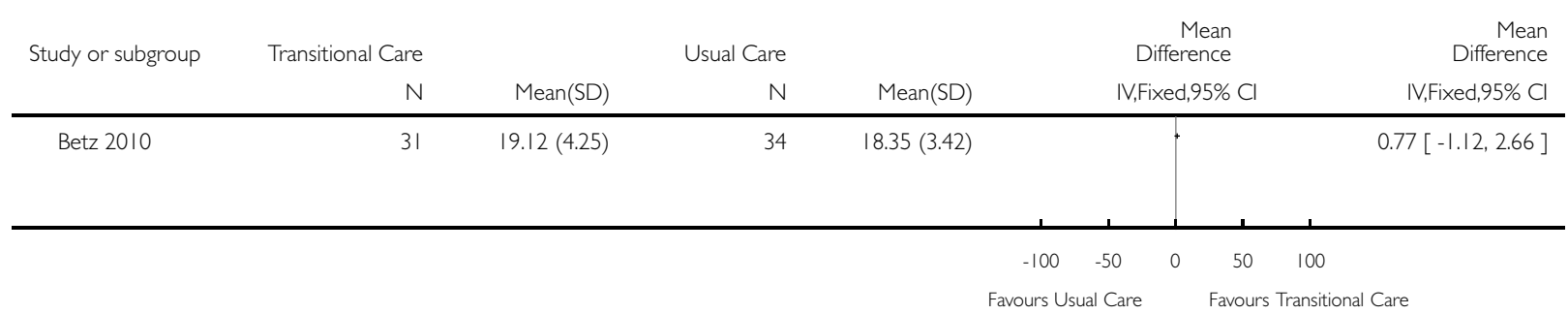


Analysis I.4. Comparison I Transtional care versus usual care, Outcome 4 Transition Readiness Assessment Questionnaire (TRAQ)..

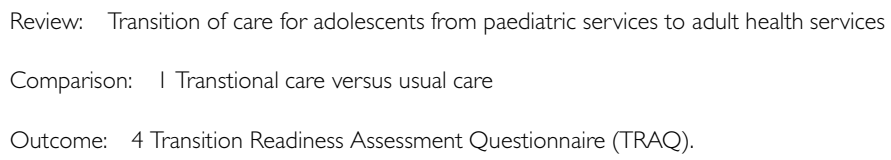

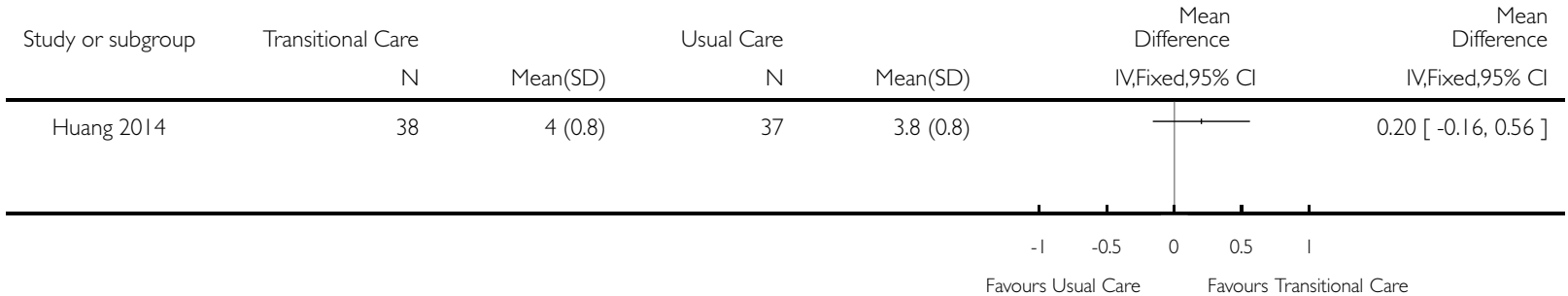

Analysis I.5. Comparison I Transtional care versus usual care, Outcome 5 TRAQ (self-management).

Review: Transition of care for adolescents from paediatric services to adult health services

Comparison: I Transtional care versus usual care

Outcome: 5 TRAQ (self-management)

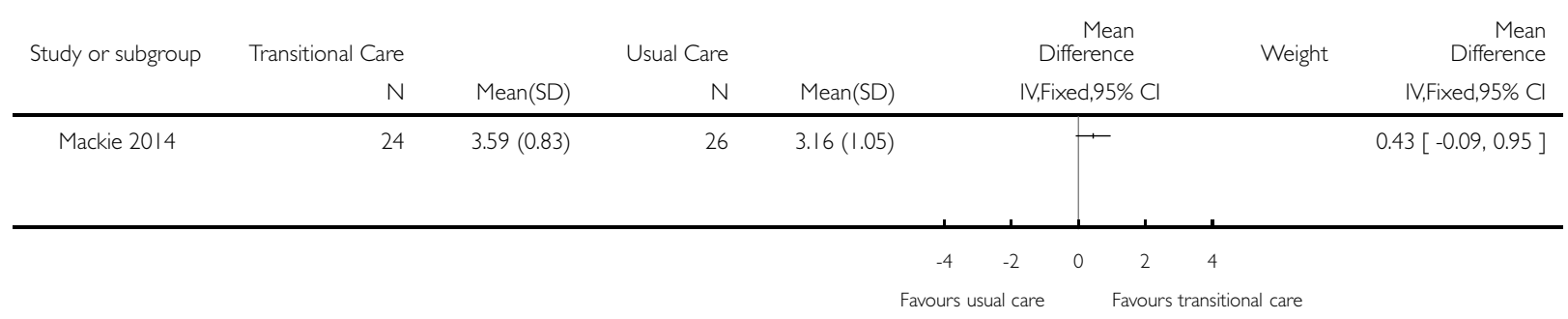




\section{Analysis I.6. Comparison I Transtional care versus usual care, Outcome 6 TRAQ (Self-advocacy).}

Review: Transition of care for adolescents from paediatric services to adult health services

Comparison: I Transtional care versus usual care

Outcome: 6 TRAQ (Self-advocacy)

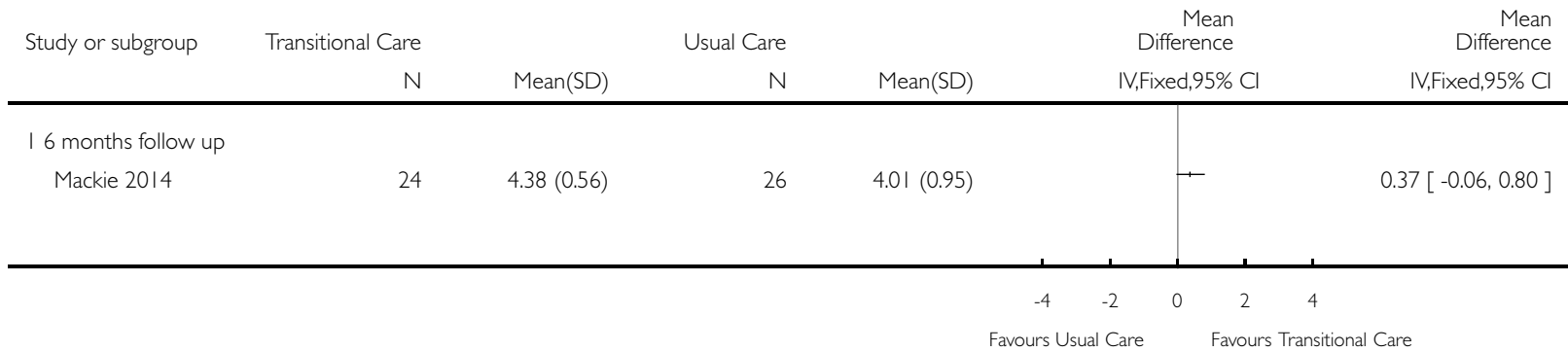

Analysis I.7. Comparison I Transtional care versus usual care, Outcome 7 Health-related self-efficacy (PAM).

Review: Transition of care for adolescents from paediatric services to adult health services

Comparison: | Transtional care versus usual care

Outcome: 7 Health-related self-efficacy (PAM)

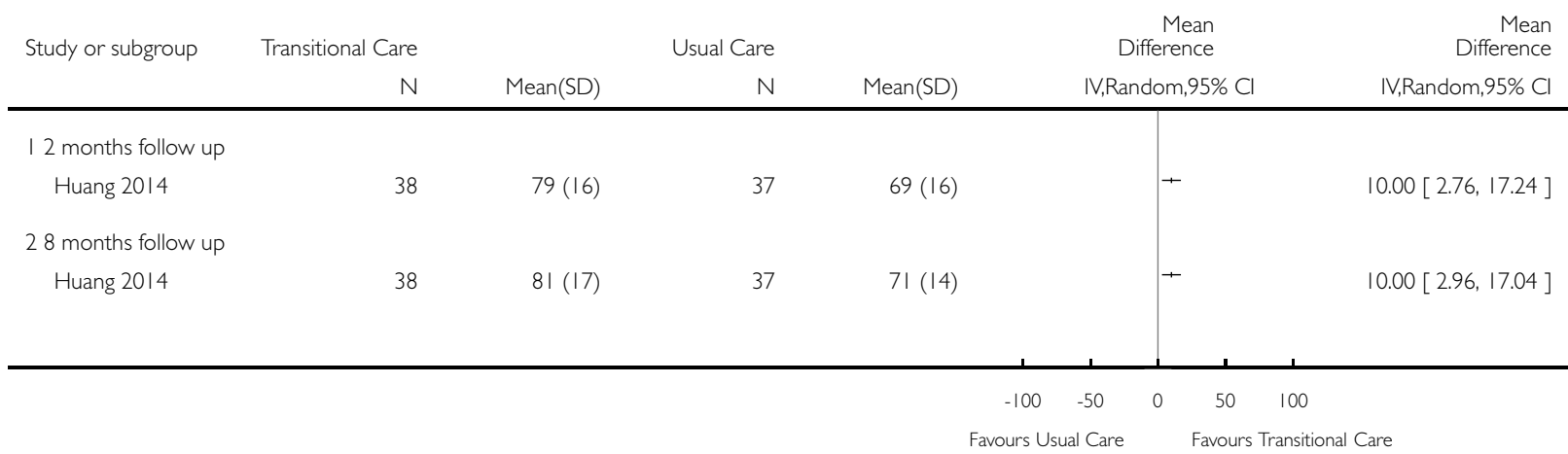




\section{Analysis I.8. Comparison I Transtional care versus usual care, Outcome 8 Patient initiated}

communications.

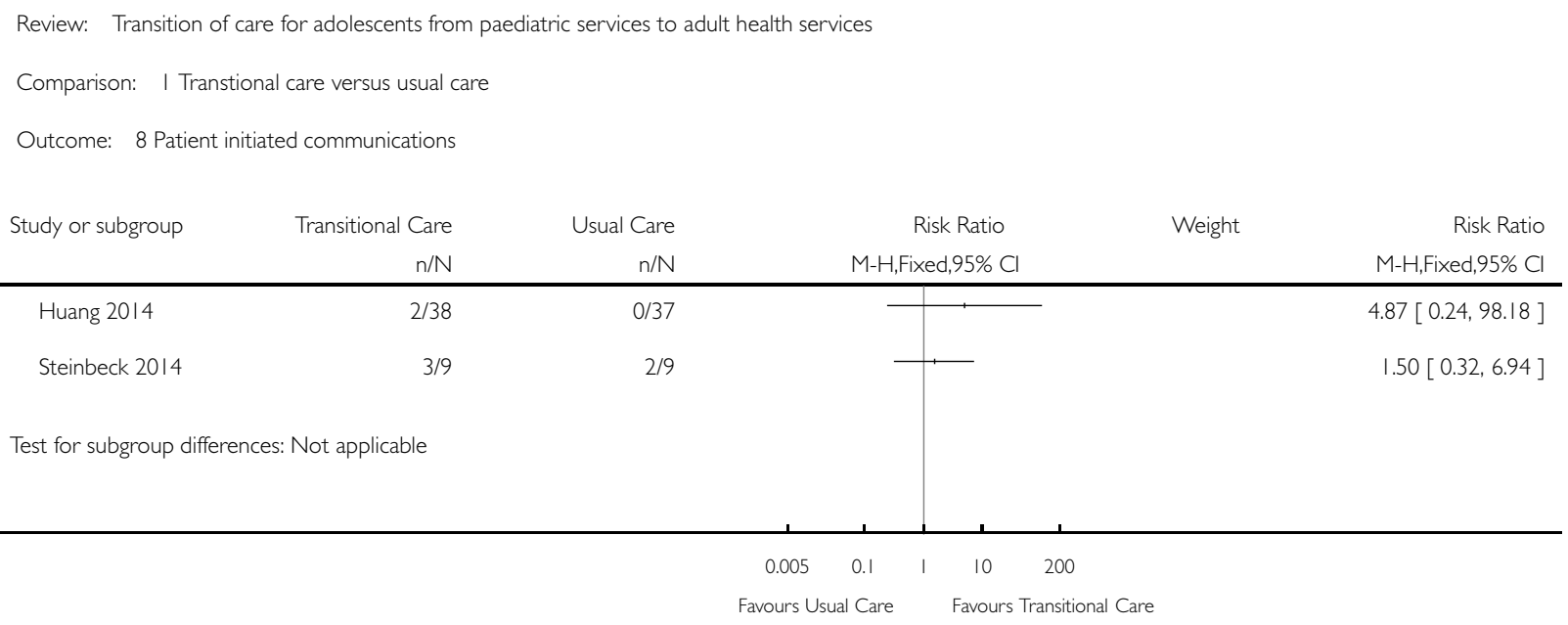

\section{Analysis I.9. Comparison I Transtional care versus usual care, Outcome 9 MyHeart.}

Review: Transition of care for adolescents from paediatric services to adult health services

Comparison: I Transtional care versus usual care

Outcome: 9 MyHeart

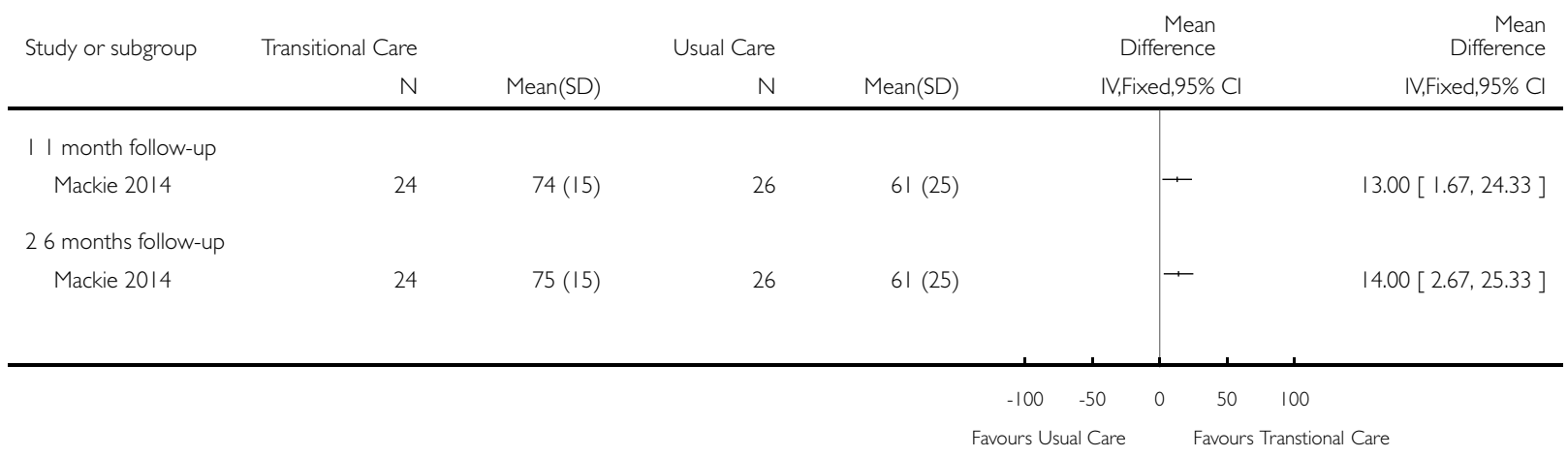


Analysis I.I0. Comparison I Transtional care versus usual care, Outcome I0 TRAQ (Self-advocacy).

Review: Transition of care for adolescents from paediatric services to adult health services

Comparison: I Transtional care versus usual care

Outcome: 10 TRAQ (Self-advocacy)

\begin{tabular}{|c|c|c|c|c|c|c|c|}
\hline \multirow[t]{2}{*}{ Study or subgroup } & Transitional Care & \multicolumn{3}{|c|}{ Usual Care } & \multirow{2}{*}{$\begin{array}{c}\text { Mean } \\
\text { Difference } \\
\text { IV,Fixed,95\% Cl }\end{array}$} & \multirow[t]{2}{*}{ Weight } & \multirow{2}{*}{$\begin{array}{r}\text { Mean } \\
\text { Difference } \\
\text { IV,Fixed,95\% Cl }\end{array}$} \\
\hline & $\mathrm{N}$ & Mean(SD) & $\mathrm{N}$ & Mean(SD) & & & \\
\hline Mackie 2014 & 24 & $4.38(0.56)$ & 26 & $4.01(0.95)$ & & & $0.37[-0.06,0.80]$ \\
\hline
\end{tabular}

Test for subgroup differences: Not applicable

\begin{tabular}{|c|c|c|c|c|}
\hline-1 & -0.5 & 0 & 0.5 & I \\
\hline
\end{tabular}

\section{Analysis I.I I. Comparison I Transtional care versus usual care, Outcome II Transfer from child to} adolescent health services.

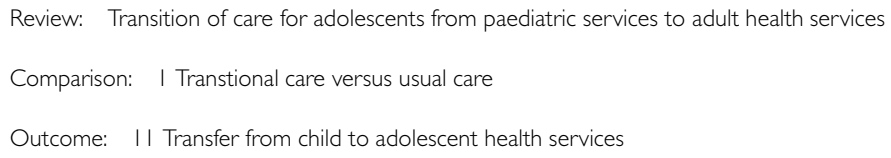

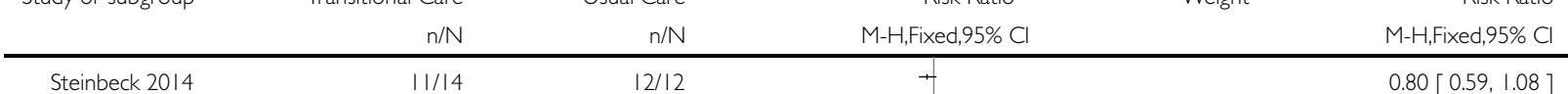


Analysis I.12. Comparison I Transtional care versus usual care, Outcome I 2 diabetes related hospitalizations in previous 12 months.

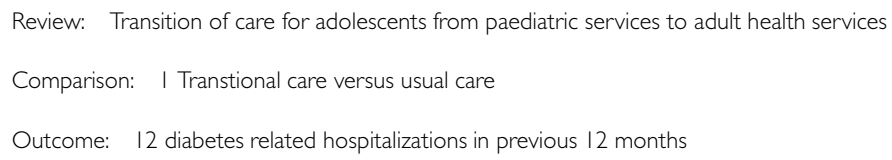

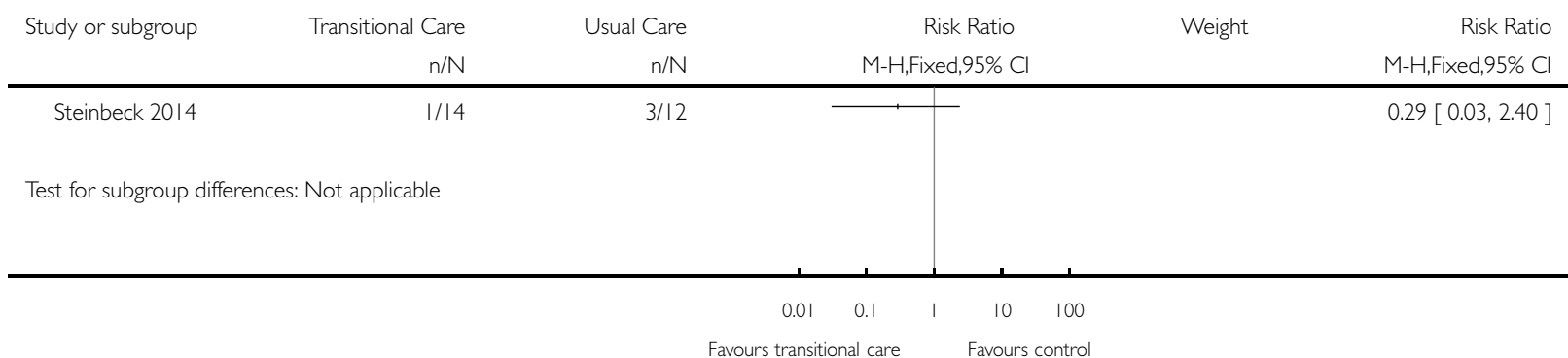

\section{A P P E N D I C E S}

\section{Appendix I. Search strategies}

Ovid MEDLINE(R) In-Process \& Other Non-Indexed Citations and Ovid MEDLINE(R) - (OvidSP) [1946-present] Search date: 19 June 2015

\section{Adolescent/}

2 Young Adult/

3 (pediatric? or paediatric?).ti,hw.

4 (adolescent? or adolescence or teen? or teenage or teenager? or juvenile or youth or young person? or young people or young adult? or young adulthood or young men or young women or young male? or young female?).ti,ab

51 or 2 or 3 or 4

6 Adolescent Medicine/

7 Adolescent Health Services/

8 Hospitals, Pediatric/ 


\section{(Continued)}

9

$9 \quad 6$ or 7 or 8

105 or 9

11 transition*.ti.

12 (transfer? or transferred or transferral or transferring).ti

13 (transition* adj10 (care or service? or center? or centre? or clinic? or facility or facilities or unit? or department? or patient?)).ab

14 ((transfer? or transferred or transferral or transferring) adj10 (care or service? or center? or centre? or clinic? or facility or facilities or unit? or department? or patient?)).ab

15 (transition* and (adult? adj3 (care or service? or center? or centre? or clinic? or facility or facilities or unit? or department?))).ab

16 ((transfer? or transferred or transferral or transferring) and (adult? adj3 (care or service? or center? or centre? or clinic? or facility or facilities or unit? or department?))).ab

17 (transfer? or transferred or transferral or transferring or transition).ab. and (adult?.ti. or (adult-focussed or adult-oriented).ti,ab. )

18 (continuity adj3 (care or health care or healthcare or treatment? or therapy or therapies or patient? or doctor-patient or nurse patient)).ti,ab

19 "Continuity of Patient Care"/

20 Patient Transfer/

21 Patient Care Planning/

22 "Delivery of Health Care, Integrated"/

23 shared care.ti,ab.

24 shared service*.ti,ab.

25 ((healthcare or care or service*) adj3 integrat*).ti,ab.

26 or/11-25

$27 \quad 10$ and 26

28 (adolescent medicine/ or adolescent health services/) and ((care or healthcare).hw. or (og or standards).fs.)

29 (p?ediatric? adj2 adult?).ti,ab. and care.hw.

3027 or 28 or 29

Transition of care for adolescents from paediatric services to adult health services (Review) 
(Continued)

31 exp animals/ not humans/

32 “comment on".cm. or systematic review.ti. or literature review.ti. or editorial.pt. or meta-analysis.pt. or news.pt. or review.pt

$3330 \operatorname{not}(31$ or 32$)$

34 randomized controlled trial.pt.

35 controlled clinical trial.pt.

36 randomized.ab.

37 placebo.ab.

38 clinical trials as topic/

39 randomly.ab.

40 trial.ti.

4134 or 35 or 36 or 37 or 38 or 39 or 40

$42 \quad 33$ and 41

43 intervention*.ti.

44 (intervention* adj6 (clinician* or collaborat* or community or complex or DESIGN* or doctor* or educational or family doctor* or family physician* or family practitioner* or financial or GP or general practice* or hospital* or impact* or improv* or individuali? $e^{*}$ or individuali?ing or interdisciplin* or multicomponent or multi-component or multidisciplin* or multidisciplin* or multifacet* ${ }^{*}$ or multi-facet* or multimodal* or multi-modal* or personali? ${ }^{*}$ or personali?ing or pharmacies or pharmacist* or pharmacy or physician* or practitioner* or prescrib* or prescription* or primary care or professional* or provider* or regulatory or regulatory or tailor* or target* or team* or usual care)).ab

45 (collaborativ* or collaboration* or tailored or personali?ed).ti,ab

46 (exp hospitals/ or exp Hospitalization/ or exp Patients/ or exp Nurses/ or exp Nursing/) and (study.ti. or evaluation studies as topic/)

47 demonstration project*.ti,ab.

48 (pre-post or "pre test" ${ }^{*}$ or pretest* or posttest* or "post test*" or (pre adj5 post)).ti,ab

49 (pre-workshop or post-workshop or (before adj3 workshop) or (after adj3 workshop)).ti,ab

50 ((study adj3 aim?) or “our study”).ab.

51 (before adj10 (after or during)).ti,ab. 


\section{(Continued)}

52 ("quasi-experiment" ${ }^{*}$ or quasiexperiment* or "quasi random*” or quasirandom* or "quasi control*” or quasicontrol* or ((quasi* or experimental) adj3 (method* or study or trial or design*))).ti,ab,hw

53 ("time series" adj2 interrupt*).ti,ab,hw.

54 (time points adj3 (over or multiple or three or four or five or six or seven or eight or nine or ten or eleven or twelve or month* or hour? or day? or "more than")).ab

55 pilot.ti.

56 Pilot projects/

57 clinical trial.pt.

58 multicenter study.pt.

59 (multicentre or multicenter or multi-centre or multi-center).ti

60 random* $^{*}$.ti,ab. or controlled.ti.

61 (control adj3 (area or cohort? or compar? or condition or group? or intervention? or participant? or study)).ab

6243 or 44 or 45 or 46 or 47 or 48 or 49 or 50 or 51 or 52 or 53 or 54 or 55 or 56 or 57 or 58 or 59 or 60 or 61

$63 \quad 33$ and 62

6463 not 42

65 (qualitative systematic review* or (systematic review and qualitative)).mp

66 (evidence synthesis or realist synthesis).mp.

67 (Qualitative and synthesis).mp.

68 (meta-synthesis* or meta synthesis* or metasynthesis).mp.

69 (meta-ethnograph* or metaethnograph* or meta ethnograph*).mp

70 (meta-study or metastudy or meta study).mp.

7165 or 66 or 67 or 68 or 69 or 70

$72 \quad 31$ and 71

73 interview*.mp.

74 px.fs. 
(Continued)

75 qualitative.tw.

76 Qualitative Research/

$77 \quad 73$ or 74 or 75 or 76

$78 \quad 33$ and 77

7978 not $(42$ or 63$)$

80 (2012* $^{*}$ or $2013^{*}$ or $\left.2014^{*}\right) . y r, d p, e d$.

$81 \quad 42$ and 80

$82 \quad 63$ and 80

$83 \quad 72$ and 80

$84 \quad 79$ and 80

85 or $/ 81-84$

EMBASE (OvidSP) (1974 to 03 March 2014)

Search date: 19 June 2015

1 adolescent/

2 (pediatric? or paediatric?).ti,hw.

3 (adolescent? or adolescence or teen? or teenage or teenager? or juvenile or youth or young person? or young people or young adult? or young adulthood or young men or young women or young male? or young female?).ti,ab

$4 \quad 1$ or 2 or 3

5 child health care/

6 pediatric hospital/

74 or 5 or 6

8 transition*.ti.

9 (transfer? or transferred or transferral or transferring).ti

10 (transition* adj10 (care or service? or center? or centre? or clinic? or facility or facilities or unit? or department? or patient?)).ab 


\section{(Continued)}

11 ((transfer? or transferred or transferral or transferring) adj10 (care or service? or center? or centre? or clinic? or facility or facilities or unit? or department? or patient?)).ab

12 (transition* and (adult? adj3 (care or service? or center? or centre? or clinic? or facility or facilities or unit? or department?))).ab

13 ((transfer? or transferred or transferral or transferring) and (adult? adj3 (care or service? or center? or centre? or clinic? or facility or facilities or unit? or department?))).ab

14 (transfer? or transferred or transferral or transferring or transition).ab. and (adult?.ti. or (adult-focussed or adult-oriented).ti,ab. )

15 (continuity adj3 (care or health care or healthcare or treatment? or therapy or therapies or patient? or doctor-patient or nurse patient)).ti,ab

16 patient care planning/

17 integrated health care system/

18 shared care.ti,ab.

19 shared service*.ti,ab.

20 ((healthcare or care or service* ${ }^{*}$ adj3 integrat*).ti,ab.

218 or 9 or 10 or 11 or 12 or 13 or 14 or 15 or 16 or 17 or 18 or 19 or 20

227 and 21

23 (p?ediatric? adj2 adult?).ti,ab. and care.hw.

2422 or 23

25 (animal model? or animal experiment? or animal study? or animal trial? or canine or feline or bovine or cow or cows or mice or dog? or cat or cats or rabbit? or rat or rats or veterinar\$).ti. or (animal or veterinary).hw

26 (editorial or letter or note or "review" or trade or survey).pt

27 meta-analysis/ or systematic review/ or "literature review".ti. or "systematic review".ti. or (meta-analy\$ or metaanalyt $\$$ ).ti

2825 or 26 or 27

$2924 \operatorname{not} 28$

30 randomized controlled trial/

31 crossover-procedure/

32 double-blind procedure/

Transition of care for adolescents from paediatric services to adult health services (Review)

Copyright @ 2016 The Cochrane Collaboration. Published by John Wiley \& Sons, Ltd. 
(Continued)

33 single-blind procedure/

34 (random $\$$ or factorial $\$$ or crossover $\$$ or cross-over $\$$ or placebo $\$$ or (doubl\$ adj blind $\$$ ) or (singl\$ adj blind $\$$ ) or assign $\$$ or allocat\$ or volunteer\$).ti,ab

35 or $/ 30-34$

3629 and 35

37 intervention*.ti.

38 (intervention* adj6 (clinician* or collaborat* or community or complex or DESIGN* or doctor* or educational or family doctor* or family physician* or family practitioner* or financial or GP or general practice* or hospital* or impact* or improv* or individuali? $e^{*}$ or individuali?ing or interdisciplin* or multicomponent or multi-component or multidisciplin* or multidisciplin* ${ }^{*}$ multifacet* ${ }^{*}$ or multi-facet* or multimodal* or multi-modal* or personali? $\mathrm{e}^{*}$ or personali?ing or pharmacies or pharmacist* or pharmacy or physician* or practitioner* ${ }^{*}$ or prescrib* ${ }^{*}$ or prescription* ${ }^{*}$ or primary care or professional* or provider* $^{*}$

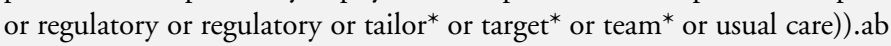

39 (collaborativ* or collaboration* or tailored or personali?ed).ti,ab

40 demonstration project*.ti,ab.

41 (pre-post or "pre test*" or pretest* or posttest* or "post test*" or (pre adj5 post)).ti,ab

42 (pre-workshop or post-workshop or (before adj3 workshop) or (after adj3 workshop)).ti,ab

43 ((study adj3 aim?) or “our study”).ab.

44 (before adj10 (after or during)).ti,ab.

45 (“quasi-experiment*” or quasiexperiment* or “quasi random*” or quasirandom* or "quasi control*” or quasicontrol* or ((quasi* or experimental) adj3 (method* or study or trial or design*))).ti,ab,hw

46 (“time series” adj2 interrupt*).ti,ab.

47 (time points adj3 (over or multiple or three or four or five or six or seven or eight or nine or ten or eleven or twelve or month* or hour? or day? or "more than")).ab

48 pilot.ti.

49 *experimental design/ or *pilot study/ or quasi experimental study/

50 (multicentre or multicenter or multi-centre or multi-center).ti

51 random*.ti,ab. or controlled.ti.

52 (control adj3 (area or cohort? or compar? or condition or group? or intervention? or participant? or study)).ab 


\section{(Continued)}

53 or $/ 37-52$

5429 and 53

$55 \quad 54 \operatorname{not} 36$

56 (qualitative systematic review* or (systematic review and qualitative)).mp

57 (evidence synthesis or realist synthesis).mp.

58 (Qualitative and synthesis).mp.

59 (meta-synthesis* or meta synthesis* or metasynthesis).mp.

60 (meta-ethnograph* or metaethnograph* or meta ethnograph*).mp

61 (meta-study or metastudy or meta study).mp.

6256 or 57 or 58 or 59 or 60 or 61

6324 and 62

64 interview*.tw.

65 qualitative*.tw.

66 exp health care organization/

$67 \quad 64$ or 65 or 66

$68 \quad 29$ and 67

$6968 \operatorname{not}(36$ or 55$)$

$70 \quad\left(2012^{*}\right.$ or $2013^{*}$ or $\left.2014^{*}\right) . y r, d p, e m$.

7136 and 70

$72 \quad 55$ and 70

$73 \quad 63$ and 70

$74 \quad 69$ and 70

75 or $/ 71-74$

Cochrane Central Register of Controlled Trials - 2014, Issue 1

Search date: 19 June 2015 


\begin{tabular}{|c|c|}
\hline$\# 1$ & $\begin{array}{l}\text { (pediatric? or paediatric? or adolescent? or adolescence or teen? or teenage or teenager? or juvenile or youth or young person? } \\
\text { or young people or young adult? or young adulthood or young men or young women or young male? or young female?):ti,ab, } \\
\text { kw }\end{array}$ \\
\hline$\# 2$ & (transition*):ti \\
\hline \#3 & (transfer? or transferred or transferral or transferring):ti \\
\hline \#4 & $\begin{array}{l}\text { (transition* near (care or service? or center? or centre? or clinic? or facility or facilities or unit? or department? or patient?)):ti, } \\
\mathrm{ab}, \mathrm{kw}\end{array}$ \\
\hline$\# 5$ & $\begin{array}{l}\text { ((transfer? or transferred or transferral or transferring) near (care or service? or center? or centre? or clinic? or facility or facilities } \\
\text { or unit? or department? or patient?)):ti,ab,kw }\end{array}$ \\
\hline \#6 & (transition* and (adult? near (care or service? or center? or centre? or clinic? or facility or facilities or unit? or department?))):ab \\
\hline \#7 & $\begin{array}{l}\text { ((transfer? or transferred or transferral or transferring) and (adult? near (care or service? or center? or centre? or clinic? or facility } \\
\text { or facilities or unit? or department?))):ti,ab,kw }\end{array}$ \\
\hline \#8 & $\begin{array}{l}\text { (continuity near (care or health care or healthcare or treatment? or therapy or therapies or patient? or doctor-patient or nurse } \\
\text { patient)):ti,ab,kw }\end{array}$ \\
\hline \#9 & "shared care" OR "shared service*":ti,ab,kw \\
\hline$\# 10$ & ((healthcare or care or service* $)$ near integrat*):ti,ab,kw \\
\hline$\# 11$ & (\#2 OR \#3 OR \#4 OR \#5 OR \#6 OR \#7 OR \#8 OR \#9 OR \#10) \\
\hline \#12 & (\#1 AND \#11) \\
\hline
\end{tabular}

CINAHL - (EBSCOHost) (1982 to 2015)

Search date: 19 June 2015

S1 (MH “Young Adult") OR (MH “Adolescence+")

S2 TI ( pediatric? or paediatric?) OR MW ( pediatric? or paediatric?)

S3 TI ( adolescent? or adolescence or teen? or teenage or teenager? or juvenile or youth or young person? or young people or young adult? or young adulthood or young men or young women or young male? or young female? ) OR AB ( adolescent? or adolescence or teen? or teenage or teenager? or juvenile or youth or young person? or young people or young adult? or young adulthood or young men or young women or young male? or young female? )

S4 S1 or S2 or S3

S5 (MH “Adolescent Medicine”)

S6 (MH “Adolescent Health Services”)

Transition of care for adolescents from paediatric services to adult health services (Review)

Copyright $\odot 2016$ The Cochrane Collaboration. Published by John Wiley \& Sons, Ltd. 
(Continued)

S7 (MH "Hospitals, Pediatric")

S8 $\quad$ S4 or S5 or S6 or S7

S9 TI transition*

S10 TI transfer? or transferred or transferral or transferring

S11 AB (transition* n10 (care or service? or center? or centre? or clinic? or facility or facilities or unit? or department? or patient?))

S12 AB ((transfer? or transferred or transferral or transferring) n10 (care or service? or center? or centre? or clinic? or facility or facilities or unit? or department? or patient?))

S13 AB (transition* and (adult? n3 (care or service? or center? or centre? or clinic? or facility or facilities or unit? or department?)))

S14 AB ((transfer? or transferred or transferral or transferring) and (adult? n3 (care or service? or center? or centre? or clinic? or facility or facilities or unit? or department?)))

S15 AB ( transfer? or transferred or transferral or transferring or transition ) AND TI adult?

S16 AB ( transfer? or transferred or transferral or transferring or transition ) AND AB ( adult-focussed or adult-oriented )

S17 AB ( transfer? or transferred or transferral or transferring or transition ) AND TI ( adult-focussed or adult-oriented )

S18 AB ( (continuity n3 (care or health care or healthcare or treatment? or therapy or therapies or patient? or doctor-patient or nurse patient)) ) AND TI ( (continuity n3 (care or health care or healthcare or treatment? or therapy or therapies or patient? or doctor-patient or nurse patient)) )

S19 (MH "Continuity of Patient Care")

S20 (MH “Transfer, Discharge”)

S21 (MH "Patient Care Plans")

S22 (MH “Health Care Delivery, Integrated”)

S23 TI shared care OR AB shared care

S24 TI shared service* OR AB shared service*

S25 TI ( ((healthcare or care or service* $) \mathrm{n} 3$ integrat $\left.\left.^{*}\right)\right)$ OR AB ( ((healthcare or care or service* $) \mathrm{n} 3$ integrat*$\left.\left.^{*}\right)\right)$

S26 S9 or S10 or S11 or S12 or S13 or S14 or S15 or S16 or S17 or S18 or S19 or S20 or S21 or S22 or S23 or S24 or S25

S27 S8 and S26 Limiters - Clinical Queries: Therapy - High Sensitivity

S28 S8 and S26

Transition of care for adolescents from paediatric services to adult health services (Review)

Copyright @ 2016 The Cochrane Collaboration. Published by John Wiley \& Sons, Ltd. 
S30 TI ( intervention* or multiintervention* or multi-intervention* or postintervention* or post-intervention* or preintervention* or pre-intervention* ${ }^{*}$ ) or $\mathrm{AB}$ ( intervention* or multiintervention* or multi-intervention* or postintervention* or post-intervention* or preintervention* or pre-intervention*)

S31 TI ( pre-test* or pretest* or posttest* or post-test* ) or AB ( pre-test* or pretest* or posttest* or "post test*) OR TI ( preimplement*” or pre-implement* ${ }^{*}$ or $\mathrm{AB}$ ( pre-implement* or preimplement*)

S32 MH Experimental Studies or Community Trials or Community Trials or Pretest-Posttest Design + or Quasi-Experimental Studies + Pilot Studies or Policy Studies + Multicenter Studies

S33 TI ( (comparative N2 study) or (comparative N2 studies) or evaluation study or evaluation studies ) or AB ( (comparative N2 study) or (comparative N2 studies) or evaluation study or evaluation studies )

S34 MH "Multiple Time Series" or MH “Time Series”

S35 TI pre w7 post or $\mathrm{AB}$ pre w7 post

S36 TI ( ( quasi-experiment* or quasiexperiment* or quasi-random* or quasirandom* or quasi control* or quasicontrol* ${ }^{*}$ or quasi* $^{*}$ W3 method* or quasi* W3 study or quasi* W3 studies or quasi* W3 trial or quasi* W3 design* or experimental W3 method* or experimental W3 study or experimental W3 studies or experimental W3 trial or experimental W3 design* )) or AB ( ( quasi-experiment* or quasiexperiment* or quasi-random* or quasirandom* or quasi control* or quasicontrol* or quasi* W3 method* or quasi* W3 study or quasi* W3 studies or quasi* W3 trial or quasi* W3 design* or experimental W3 method* or experimental W3 study or experimental W3 studies or experimental W3 trial or experimental W3 design*) )

S37 TI ( (time point*) or (period* $n 4$ interrupted) or (period* $n 4$ multiple) or (period* $n 4$ time) or (period* $n 4$ various) or (period* $\mathrm{n} 4$ varying) or (period* $\mathrm{n} 4$ week $^{*}$ ) or (period* $\mathrm{n} 4$ month $^{*}$ ) or (period* $\mathrm{n} 4$ year*) ) or AB ( (time point*) or (period* $\mathrm{n} 4$ interrupted) or (period* $\mathrm{n} 4$ multiple) or (period* $\mathrm{n} 4$ time) or (period* $\mathrm{n} 4$ various) or (period* $\mathrm{n} 4$ varying) or (period* $\mathrm{n} 4$ week $^{*}$ ) or (period* $n 4$ month*) or (period* $n 4$ year*) )

S38 $\mathrm{AB}$ ( before* $\mathrm{n} 10$ during or before $\mathrm{n} 10$ after ) or $\mathrm{AU}$ ( before* $\mathrm{n} 10$ during or before $\mathrm{n} 10$ after )

S39 TI time series or $\mathrm{AB}$ time series

S40 AB "before-and-after"

S41 (MH “Pilot Studies")

S42 TI pilot

S43 TI ( collaborativ* or collaboration* or tailored or personalised or personalized ) or AB ( collaborativ* or collaboration* or tailored or personalised or personalized )

S44 (intervention $\mathrm{n} 6$ clinician*) or (intervention $\mathrm{n} 6$ community) or (intervention $\mathrm{n} 6$ complex) or (intervention $\mathrm{n} 6$ design*) or (intervention $\mathrm{n} 6$ doctor*) $^{*}$ or (intervention $\mathrm{n} 6$ educational) or (intervention $\mathrm{n} 6$ family doctor*) or (intervention $\mathrm{n} 6$ family physician*) or (intervention n6 family practitioner*) or (intervention n6 financial) or (intervention n6 GP) or (intervention n6 general practice*) Or (intervention n6 hospital*) or (intervention n6 impact*) Or (intervention n6 improv*) or (intervention 
$\mathrm{n} 6$ individualize*) Or (intervention $\mathrm{n} 6$ individualise*) or (intervention $\mathrm{n} 6$ individualizing) or (intervention n6 individualising) or (intervention $\mathrm{n} 6$ interdisciplin*) or (intervention $\mathrm{n} 6$ multicomponent) or (intervention n 6 multi-component) or (intervention $\mathrm{n} 6$ multidisciplin*) or (intervention $\mathrm{n} 6$ multi-disciplin*) or (intervention $\mathrm{n} 6$ multifacet $^{*}$ ) or (intervention n 6 multifacet $^{*}$ ) or (intervention $\mathrm{n} 6$ multimodal $^{*}$ ) or (intervention $\mathrm{n} 6$ multi-modal $^{*}$ ) or (intervention $\mathrm{n} 6$ personalize*) or(intervention $\mathrm{n} 6$ personalise* $\mathrm{s}^{*}$ or (intervention $\mathrm{n} 6$ personalizing) or (intervention $\mathrm{n} 6$ personalising) or (intervention n6 pharmaci*) or (intervention $\mathrm{n} 6$ pharmacist*) or (intervention $\mathrm{n} 6$ pharmacy) or (intervention $\mathrm{n} 6$ physician*) or (intervention n6 practitioner*)

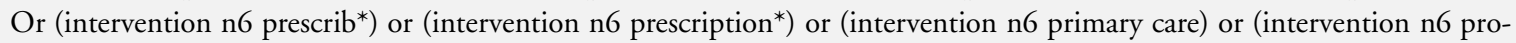

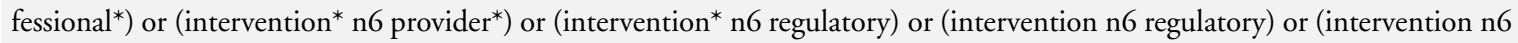
tailor ${ }^{*}$ or (intervention $\mathrm{n} 6$ target*) or (intervention $\mathrm{n} 6$ team*) or (intervention $\mathrm{n} 6$ usual care)

S45 TI ( demonstration project OR demonstration projects OR preimplement* or pre-implement* or post-implement* or postimplement $^{*}$ ) or $\mathrm{AB}$ ( demonstration project OR demonstration projects OR preimplement* or pre-implement* or post-implement* or postimplement*)

S46 TI ( pre-workshop or preworkshop or post-workshop or postworkshop or (before $\mathrm{n} 3$ workshop) or (after n3 workshop) ) or $\mathrm{AB}$ ( pre-workshop or preworkshop or post-workshop or postworkshop or (before n3 workshop) or (after n3 workshop))

S47 TI ( trial or (study n3 aim) or "our study" ) or AB ( (study n3 aim) or "our study")

S48 TI random* OR controlled

S49 TI ( multicentre or multicenter or multi-centre or multi-center ) or AB random*

S50 TI ( (control w3 area) or (control w3 cohort*) or (control w3 compar*) or (control w3 condition) or (control w3 group*) or (control w3 intervention*) or (control w3 participant*) or (control w3 study) ) or AB ( (control w3 area) or (control w3 cohort $^{*}$ ) or (control w3 compar*) or (control w3 condition) or (control w3 group ${ }^{*}$ ) or (control w3 intervention*) or (control w3 participant*) or (control w3 study) )

S51 TI ( (time points $n 3$ over) or (time points $n 3$ multiple) or (time points $n 3$ three) or (time points $n 3$ four) or (time points $n 3$ five) or (time points $n 3$ six) or (time points $n 3$ seven) or (time points $n 3$ eight) or (time points $n 3$ nine) or (time points $n 3$ ten)

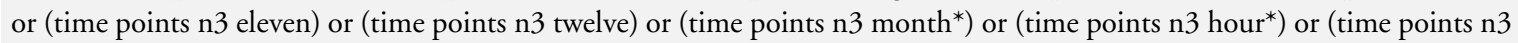
day*) $^{*}$ or (time points $\mathrm{n} 3$ "more than") ) or $\mathrm{AB}$ ( (time points $\mathrm{n} 3$ over) or (time points $\mathrm{n} 3$ multiple) or (time points $\mathrm{n} 3$ three) or (time points $n 3$ four) or (time points $n 3$ five) or (time points $n 3$ six) or (time points $n 3$ seven) or (time points $n 3$ eight) or (time points $\mathrm{n} 3$ nine) or (time points $\mathrm{n} 3$ ten) or (time points $\mathrm{n} 3$ eleven) or (time points $\mathrm{n} 3$ twelve) or (time points $\mathrm{n} 3$ month*) or (time points $\mathrm{n} 3$ hour*) or (time points $\mathrm{n} 3$ day $^{*}$ ) or (time points $\mathrm{n} 3$ "more than") )

S52 S29 or S30 or S31 or S32 or S33 or S34 or S35 or S36 or S37 or S38 or S39 or S40 or S41 or S42 or S43 or S44 or S45 or $\mathrm{S} 46$ or $\mathrm{S} 47$ or $\mathrm{S} 48$ or $\mathrm{S} 49$ or $\mathrm{S} 50$ or $\mathrm{S} 51$

\section{S53 (MH “Attitude+")}

S54 (MH “Interviews+”)

S55 (MH “Qualitative Studies+”)

S56 S53 or S54 or S55

S57 TI qualitative systematic review OR AB qualitative systematic review 


\section{(Continued)}

S58 TI ( qualitative AND systematic review ) OR AB ( qualitative AND systematic review )

S59 TI ( evidence synthesis or realist synthesis ) OR AB ( evidence synthesis or realist synthesis )

S60 TI ( Qualitative and synthesis ) OR AB ( Qualitative and synthesis )

S61 TI ( meta-synthesis* or meta synthesis* or metasynthesis ) OR AB ( meta-synthesis* or meta synthesis* or metasynthesis )

S62 TI ( meta-ethnograph* or metaethnograph* or meta ethnograph*) OR AB ( meta-ethnograph* or metaethnograph* or meta ethnograph*)

S63 TI ( meta-study or metastudy or meta study) OR AB ( meta-study or metastudy or meta study )

S64 S57 or S58 or S59 or S60 or S61 or S62 or S63

S65 S8 AND S26 AND S52

S66 S28 and S56

S67 S28 and S64

S68 (ZR “2012”) or (ZR “2013”) or (ZR “2014”) or (ZD 2012*) or (ZD 2013*) OR (ZD 2014*)

S69 S27 AND S68

S70 S65 AND S68

S71 S66 AND S68

S72 S67 AND S68

S73 S69 OR S70 OR S71 OR S72

Health Management Information Consortium (HMIC) - (OvidSP) (1979 to January 2014)

Search date: 19 June 2015

1 young people/ or early teenagers/ or late teenagers/

2 (pediatric? or paediatric?).ti,hw.

3 (adolescent? or adolescence or teen? or teenage or teenager? or juvenile or youth or young person? or young people or young adult? or young adulthood or young men or young women or young male? or young female?).ti,ab

$4 \quad 1$ or 2 or 3

5 transition*.ti. 


\section{(Continued)}

$6 \quad$ (transfer? or transferred or transferral or transferring).ti

7 (transition* adj10 (care or service? or center? or centre? or clinic? or facility or facilities or unit? or department? or patient?)).ab

8 ((transfer? or transferred or transferral or transferring) adj10 (care or service? or center? or centre? or clinic? or facility or facilities or unit? or department? or patient?)).ab

9 (transition* and (adult? adj3 (care or service? or center? or centre? or clinic? or facility or facilities or unit? or department?))).ab

10 ((transfer? or transferred or transferral or transferring) and (adult? adj3 (care or service? or center? or centre? or clinic? or facility or facilities or unit? or department?))).ab

11 (transfer? or transferred or transferral or transferring or transition).ab. and (adult?.ti. or (adult-focussed or adult-oriented).ti,ab. )

12 (continuity adj3 (care or health care or healthcare or treatment? or therapy or therapies or patient? or doctor-patient or nurse patient)).ti,ab

13 "continuity of patient care"/

14 patient transfer/

15 integrated care/

16 shared care.ti,ab.

17 shared service*.ti,ab.

18 ((healthcare or care or service* ${ }^{*}$ adj3 integrat $\left.{ }^{*}\right) . t i, a b$.

195 or 6 or 7 or 8 or 9 or 10 or 11 or 12 or 13 or 14 or 15 or 16 or 17 or 18

$20 \quad 4$ and 19

21 exp Young peoples health services/

22 (p?ediatric? adj2 adult?).ti,ab. and care.hw.

2320 or 21 or 22

$24\left(2012^{*}\right.$ or $2013^{*}$ or $\left.2014^{*}\right) \cdot y r, d p$.

$25 \quad 23$ and 24

PsycINFO (OvidSP) (1967 to February Week 4 2014)

Search date: 19 June 2015 
1 adolescent development/

2 (pediatric? or paediatric?).ti,hw.

3 (adolescent? or adolescence or teen? or teenage or teenager? or juvenile or youth or young person? or young people or young adult? or young adulthood or young men or young women or young male? or young female?).ti,ab

$4 \quad 1$ or 2 or 3

5 adolescent psychiatry/

64 or 5

7 transition*.ti.

$8 \quad$ (transfer? or transferred or transferral or transferring).ti

9 (transition* adj10 (care or service? or center? or centre? or clinic? or facility or facilities or unit? or department? or patient?)).ab

10 ((transfer? or transferred or transferral or transferring) adj10 (care or service? or center? or centre? or clinic? or facility or facilities or unit? or department? or patient?)).ab

11 (transition* and (adult? adj3 (care or service? or center? or centre? or clinic? or facility or facilities or unit? or department?))).ab

12 ((transfer? or transferred or transferral or transferring) and (adult? adj3 (care or service? or center? or centre? or clinic? or facility or facilities or unit? or department?))).ab

13 (transfer? or transferred or transferral or transferring or transition).ab. and (adult?.ti. or (adult-focussed or adult-oriented).ti,ab. )

14 (continuity adj3 (care or health care or healthcare or treatment? or therapy or therapies or patient? or doctor-patient or nurse patient)).ti,ab

15 client transfer/

16 "continuum of care"/

17 exp treatment planning/

18 integrated services/

19 shared care.ti,ab.

20 shared service*.ti,ab.

21 ((healthcare or care or service*) adj3 integrat* ${ }^{*}$.ti,ab.

227 or 8 or 9 or 10 or 11 or 12 or 13 or 14 or 15 or 16 or 17 or 18 or 19 or 20 or 21

Transition of care for adolescents from paediatric services to adult health services (Review)

Copyright (c) 2016 The Cochrane Collaboration. Published by John Wiley \& Sons, Ltd. 
(Continued)

236 and 22

24 (Adolescent Development/ or Pediatrics/) and (Mental Health Services/ or Health Care Services/)

25 (p?ediatric? adj2 adult?).ti,ab. and care.hw.

2623 or 24 or 25

27 limit 26 to ("comment/reply" or editorial or letter or review-book or review-media or review-software \& other or reviews)

$28 \quad 26$ not 27

29 (double-blind or random* assigned or control).tw.

$30 \quad 28$ and 29

31 intervention*.ti.

32 (intervention* adj6 (clinician* or collaborat* or community or complex or DESIGN* or doctor* or educational or family doctor* or family physician* or family practitioner* or financial or GP or general practice* or hospital* or impact* or improv* $^{*}$ or individuali? $e^{*}$ or individuali?ing or interdisciplin* or multicomponent or multi-component or multidisciplin* or multidisciplin* or multifacet* or multi-facet* or multimodal* or multi-modal* or personali?e* or personali?ing or pharmacies or pharmacist* or pharmacy or physician* or practitioner* or prescrib* or prescription* or primary care or professional* or provider*

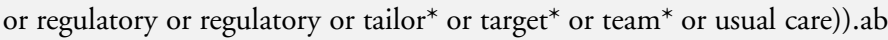

33 (collaborativ* or collaboration* or tailored or personali?ed).ti,ab

34 demonstration project*.ti,ab.

35 (pre-post or "pre test*" or pretest* or posttest* or "post test*" or (pre adj5 post)).ti,ab

36 (pre-workshop or post-workshop or (before adj3 workshop) or (after adj3 workshop)).ti,ab

37 ((study adj3 aim?) or “our study”).ab.

38 (before adj10 (after or during)).ti,ab.

39 ("quasi-experiment*" or quasiexperiment* or "quasi random*” or quasirandom* or "quasi control*” or quasicontrol* or ((quasi* or experimental) adj3 (method* or study or trial or design*))).ti,ab,hw

40 (“time series” adj2 interrupt*).ti,ab,hw.

41 (time points adj3 (over or multiple or three or four or five or six or seven or eight or nine or ten or eleven or twelve or month* or hour? or day? or "more than")).ab

42 pilot.ti.

43 intervention/

Transition of care for adolescents from paediatric services to adult health services (Review)

Copyright $\odot 2016$ The Cochrane Collaboration. Published by John Wiley \& Sons, Ltd. 


\section{(Continued)}

44 clinical trials/

45 (multicentre or multicenter or multi-centre or multi-center).ti

46 random*.ti,ab. or controlled.ti.

47 (control adj3 (area or cohort? or compar? or condition or group? or intervention? or participant? or study)).ab

4831 or 32 or 33 or 34 or 35 or 36 or 37 or 38 or 39 or 40 or 41 or 42 or 43 or 44 or 45 or 46 or 47

4928 and 48

$50 \quad 49$ not 30

51 (qualitative systematic review* or (systematic review and qualitative)).mp

52 (evidence synthesis or realist synthesis).mp.

53 (Qualitative and synthesis).mp.

54 (meta-synthesis* or meta synthesis* or metasynthesis).mp.

55 (meta-ethnograph* or metaethnograph* or meta ethnograph*).mp

56 (meta-study or metastudy or meta study).mp.

5751 or 52 or 53 or 54 or 55 or 56

$58 \quad 26$ and 57

59 experience*.mp.

60 interview*.tw.

61 qualitative*.tw.

6259 or 60 or 61

6326 and 62

$6463 \operatorname{not}(30$ or 49$)$

$65\left(2012^{*}\right.$ or $2013^{*}$ or $\left.2014^{*}\right)$.yr,dp,up.

$66 \quad 30$ and 65

6750 and 65 
(Continued)

6858 and 65

6964 and 65

70 or/66-69

Science Citation Index, Social Science Citation Index, Conference Proceedings Citation Index- Science \& Conference Proceedings Citation Index- Social Science \& Humanities (Web of Knowledge) (1945 to 2015)

Search date: 19 June 2015

\#1 TITLE: (pediatric* or paediatric*) OR TOPIC: (adolescent* or adolescence or teen or teens or teenage or teenager or teenagers or juvenile or youth or "young person"” or "young people" or "young adults" or "young adult" or "young adulthood" or "young men" or "young women" or "young male" or "young female*”)

\#2 TITLE: (transition*) OR TITLE: (transfer*)

\#3 TITLE: ((transition* SAME (care or service? or center? or centre? or clinic? or facility or facilities or unit? or department? or patient?))) OR TITLE: ((transfer* SAME (care or service? or center? or centre? or clinic? or facility or facilities or unit? or department? or patient?)))

\#4 TOPIC: ((transition* SAME (care or service? or center? or centre? or clinic? or facility or facilities or unit? or department? or patient?))) OR TOPIC: ((transfer* SAME (care or service? or center? or centre? or clinic? or facility or facilities or unit? or department? or patient?)))

\#5 TOPIC: (transition* OR transfer*) AND TOPIC: ("adult care" OR "adult service*” OR "adult center" OR "adult centre*” OR "adult clinic*” OR “adult facility” OR “adult facilities" OR "adult unit" OR "adult department*”)

\#6 TOPIC: (transition* OR transfer*) AND TITLE: (adult*)

\#7 TOPIC: (transition* OR transfer*) AND TOPIC: (adult-focussed OR adult-oriented)

\#8 TOPIC: ((continuity SAME (care or health care or healthcare or treatment? or therapy or therapies or patient? or doctorpatient or nurse patient)))

\#9 TOPIC: (“integrated care” OR “integrated service*”) OR TOPIC: (“shared care” OR "shared service*”)

\#10 \#9 OR \#8 OR \#7 OR \#6 OR \#5 OR \#4 OR \#3 OR \#2

\#11 \#10 AND \#1

\#12 \#10 AND \#1

Refined by: [excluding] DOCUMENT TYPES=( LETTER OR BOOK REVIEW OR NOTE OR BIOGRAPHICAL ITEM

OR REVIEW OR EDITORIAL MATERIAL OR CORRECTION OR CORRECTION ADDITION )

\#13 TOPIC: ((random* or blind* or allocat* or assign* ${ }^{*}$ or trial* or placebo* ${ }^{*}$ or crossover* or cross-over $\left.{ }^{*}\right)$ )

\#14 \#13 AND \#12

Transition of care for adolescents from paediatric services to adult health services (Review)

Copyright @ 2016 The Cochrane Collaboration. Published by John Wiley \& Sons, Ltd. 
\#15 TITLE: (intervention*)

\#16 TOPIC: (((intervention* SAME (clinician* or collaborat* or community or complex or DESIGN* or doctor* or educational or family doctor* or family physician* or family practitioner* or financial or GP or general practice* or hospital* or impact* or improv* or individuali* $\mathrm{e}^{*}$ or individuali*ing or interdisciplin* or multicomponent or multi-component or multidisciplin* or multi-disciplin* or multifacet* or multi-facet* or multimodal* ${ }^{*}$ or multi-modal* or personali* ${ }^{*}$ or personali*ing or pharmacies or pharmacist* or pharmacy or physician* or practitioner* or prescrib* or prescription* or primary care or professional* or provider* or regulatory or regulatory or tailor* or target* or team* or usual care))))

\#17 TOPIC: ((collaborativ* OR collaboration* OR tailored OR personalised OR personalized))

\#18 TOPIC: (((demonstration OR pilot) NEXT project*))

\#19 TITLE: (pilot)

\#20 TOPIC: (((pre-post or “pre test*” or pretest* or posttest* or “post test*” or (pre SAME post))))

\#21 TOPIC: (((pre-workshop or post-workshop or (before SAME workshop) or (after SAME workshop))))

\#22 TOPIC: ((((study SAME aim*) or “our study”)))

\#23 TOPIC: (((“quasi-experiment*” or quasiexperiment* or “quasi random*” or quasirandom* or "quasi control*” or quasicontrol* or ((quasi* or experimental) SAME (method* or study or trial or design*)))))

\#24 TOPIC: (((“time series” SAME interrupt*)))

\#25 TOPIC: (((time points SAME (over or multiple or three or four or five or six or seven or eight or nine or ten or eleven or twelve or month* or hour* or day* or "more than"))))

\#26 TOPIC: ((multicentre or multicenter or multi-centre or multi-center))

\#27 TOPIC: (((control SAME (area or cohort* or compar* or condition or group* or intervention* or participant* or study))))

\#28 \#27 OR \#26 OR \#25 OR \#24 OR \#23 OR \#22 OR \#21 OR \#20 OR \#19 OR \#18 OR \#17 OR \#16 OR \#15

\#29 \#28 AND \#12

\#30 \#29 NOT \#14

\#31 TOPIC: (experience OR experiences) OR TOPIC: (interview*) OR TOPIC: (qualitative)

\#32 \#31 AND \#12

\#33 \#32 NOT (\#14 OR \#30)

\#34 \#14 Indexes=SCI-EXPANDED, SSCI, CPCI-S Timespan=2012-2014

\#35 \#30 Indexes=SCI-EXPANDED, SSCI, CPCI-S Timespan=2012-2014

Transition of care for adolescents from paediatric services to adult health services (Review)

Copyright () 2016 The Cochrane Collaboration. Published by John Wiley \& Sons, Ltd. 
\#37

EPOC Trials Register

Search date: 6 June 2012

The following search was performed in Reference Manager.The EPOC trials register is no longer being updated and all the records it contained are now available in CENTRAL. Subsequent reruns of this search were therefore not required.

\begin{tabular}{|c|c|c|}
\hline & Title, primary & $\{$ transition $\}$ and $\{$ care $\}$ \\
\hline OR & Abstract & $\{$ transition $\}$ and $\{$ care $\}$ \\
\hline OR & Abstract & $\{$ discharg $\}$ and $\{$ transition $\}$ \\
\hline OR & Abstract & $\{$ discharg $\}$ and $\{$ youth $\}$ \\
\hline OR & All Non-Indexed Fields & $\{$ discharg $\}$ and $\{$ adolesc $\}$ \\
\hline OR & All Non-Indexed Fields & $\{$ discharg $\}$ and $\{$ child $\}$ \\
\hline OR & All Non-Indexed Fields & $\{$ discharg\} and \{pediatric\} \\
\hline OR & All Non-Indexed Fields & $\{$ discharg $\}$ and $\{$ paediatric $\}$ \\
\hline OR & All Non-Indexed Fields & $\{$ transition $\}$ and $\{$ pediatric $\}$ \\
\hline OR & All Non-Indexed Fields & $\{$ transition $\}$ and $\{$ child $\}$ \\
\hline
\end{tabular}

\section{CONTRIBUTIONS OFAUTHORS}

FC, SA, KB, and PMO screened the articles found during the search, KB, FC, and PMO extracted the data for the quantitative review. FC, SA, and KB drafted the initial report, and AW and JM commented and provided content expertise. All authors read and approved the final version. 


\section{DECLARATIONSOF INTEREST}

Fiona Campbell, Philip M O’Neill, Alison While, Janet McDonagh, Katie Biggs, Susie K Aldiss, Faith Gibson, and Mark Clowes have no conflicts of interest.

\section{SOURCES OF SUPPORT}

\section{Internal sources}

- School of Health and Related Research, University of Sheffield, UK.

Support for Fiona Campbell and Katie Biggs

\section{External sources}

- NIHR Cochrane Programme Grant (Effective Practice and Organisation of Care), UK.

Methodogological, editorial and specialist information support

\section{DIFFERENCES BETWEEN PROTOCOLAND REVIEW}

The protocol states the review will combine quantitative and qualitative data (Campbell 2012); this has not been done. We have published the effectiveness review first, and will subsequently review the qualitative evidence. . 